\title{
Mechanical analysis of UMo/Al dispersion fuel
}

\author{
Gwan Yoon Jeong ${ }^{\mathrm{a}}$, Yeon Soo Kim ${ }^{\mathrm{b}}$, Dong-Seong Sohn ${ }^{\mathrm{a}^{*}}$ \\ ${ }^{a}$ Ulsan National Institute of Science and Technology, 50 UNIST-gil, Eonyang-eup Ulju-gun, Ulsan, \\ 689-798, Korea \\ ${ }^{b}$ Argonne National Laboratory, 9700 South Cass Avenue, Argonne, Illinois, 60439, USA \\ ${ }^{*}$ Corresponding author. Tel : +82-52-217-2938, Fax :+82-52-217-3008 \\ E-mail : dssohn@unist.ac.kr
}

\begin{abstract}
Deformation of fuel particles and mass transfer from the transverse end of fuel meat toward the meat center was observed. This caused plate thickness peaking at a location between the meat edge and the meat center. The underlying mechanism for this fuel volume transport is believed to be fission induced creep of the U-Mo/Al meat. Fuel meat swelling was measured using optical microscopy images of the cross sections of the irradiated test plates. The time-dependent meat swelling was modeled for use in numerical simulation. A distinctive discrepancy between the predicted and measured meat thickness was found at the meat ends, which was assumed to be due to creep-induced mass relocation from the meat end to the meat center region that was not considered in the meat swelling model. ABAQUS FEA simulation was performed to reproduce the observed phenomenon at the meat ends. Through the simulation, we obtained the effective creep rate constants for the interaction layers (IL) and aluminum matrix. In addition, we obtained the corresponding stress and strain analysis results that can be used to understand mechanical behavior of U-Mo/Al dispersion fuel.
\end{abstract}




\section{Introduction}

Uranium-molybdenum (U-Mo) alloys have been extensively studied for high power research and test reactors worldwide by the U.S. Reduced Enrichment and Test Reactor (RERTR) and other international programs. Two forms of U-Mo alloy fuel have been designed and irradiation-tested. One is a monolithic fuel form, in which a thin U-Mo alloy foil is metallurgically bonded to aluminum alloy cladding. The other is a dispersion fuel form, denoted as U-Mo/Al, composed of U-Mo fuel particles that are dispersed in an inert $\mathrm{Al}$ matrix. The fueled zone, containing the U-Mo particles and $\mathrm{Al}$ matrix, is also referred to as fuel meat. Fig. 1 illustrates the cross sections of a monolithic fuel plate and a dispersion fuel plate.

Deformation of dispersed fuel particles and mass transfer from the transverse end of fuel meat toward the transverse center has been observed in the U.S. and European irradiation tests. The driving forces of this phenomenon are the shear stresses induced by fuel meat swelling. Fuel meat volumetric swelling is a sum of swelling by fission products in the fuel particles, swelling by fission in the interaction layer (IL), and volume expansion by IL formation and volume reduction of fuel and Al matrix by IL growth.

A similar phenomenon has been analyzed in monolithic foil plates [1],[2], through which creep deformation is proposed as the underlying mechanism controlling the rate of fuel volume transport. In this case, the driving force is the stress induced by swelling in the fuel foil. Quantitative analysis and modeling of this phenomenon are simpler in the foil fuel case because of the absence of Al matrix and IL.

In the case of dispersion fuel, however, quantitative analysis and modeling for this phenomenon are more complicated due to additional consideration of both Al matrix and IL. IL growth causes a 
microstructure evolution in the meat. In terms of fuel performance and safety, meat swelling prediction, creep, and mass relocation are important.

In this paper, we examined two dispersion fuel plates. One is V6022M from the RERTR-4 test that contained spherical $\mathrm{U}-10 \mathrm{wt} \%$ Mo fuel particle dispersion in a pure Al matrix, and the other is R3R108 from the RERTR-9 test with spherical U-7 wt.\% Mo fuel particle dispersion in an Al-5 wt.\% Si matrix. These two plates were selected since they represent two example cases: V6022M was of a pure Al matrix with $6 \mathrm{~g} / \mathrm{cm}^{3}$ uranium loading, in which extensive IL formation was observed in the meat. R3R108 was of Si added $\mathrm{Al}$ matrix with $8 \mathrm{~g} / \mathrm{cm}^{3}$ fuel loading that showed IL growth suppression by the addition of Si within the matrix. R3R108 has much higher fission rate than V6022M.

This paper deals with the measurement of meat swelling using optical microscopy (OM) images and finite element analysis of meat swelling.

The finite element analysis (FEA) package ABAQUS [3] was utilized to simulate meat swelling including creep and meat mass relocation. From the analysis, creep rate constants were obtained for IL and $\mathrm{Al}$ that best fit the observed creep and meat mass relocation. The states of equivalent shear stress and creep strain in the meat were also examined to offer an explanation for the meat mass relocation. Another objective of the ABAQUS simulation was that the meat observed mass relocation in the meat is indeed reproduced by the creep mechanism combined with material properties available in the literature.

\section{Experimental data}

The two plates selected for analysis in the present study, V6022M and R3R108, were irradiated in the ATR in the RERTR-4 and -9 tests, respectively. The irradiation test data of the plates analyzed are summarized in Table 1. The plates are sub-sized plates, called 'miniplates', with dimensions of 100 
$\mathrm{mm}$ in length, $25 \mathrm{~mm}$ in width, and $1.40 \mathrm{~mm}$ in thickness. The meat dimensions are $81.3 \mathrm{~mm}$ in length, $18.5 \mathrm{~mm}$ in width, and $0.64 \mathrm{~mm}$ in thickness. The fission density (FD) distributions across the meat width of the plates are compared in Fig. 2. R3R108 plate was loaded in the ATR in a configuration that a narrow edge faced the ATR core center for irradiation life, which caused one side closest to the core to accumulate higher fission density. V6022M was also loaded in the same manner as R3R108, but it was flipped horizontally to switch sides for every irradiation cycle for FD across the plate to be more uniformly irradiated than R3R108. However, as can be noticed in Fig. 2, a slight peaking in FD at the meat edges was inevitable in V6022M.

The fission rate (FR) histories at the meat axial and transversal center for both plate are compared in Fig. 3. V6022M was irradiated for 257 effective full power days (EFPD) to achieve $78 \%$ U-235 LEU equivalent burnup and R3R108 achieved 64\% U-235 LEU equivalent burnup for 98 EFPD. Although R3R108 plate was irradiated during a shorter period, FD of R3R108 at the core side (hot side) was higher than that of V6022M due to its higher fission rate and higher power peaking.

After irradiation tests, the plates were sectioned at the axial center plane as schematically shown in Fig. 4. The exposed meat cross sections were examined through optical microscopy (OM).

\section{Post-irradiation analysis}

The cross section images of V6022M and R3R108 plates at post-irradiation examination (PIE) are shown in Fig. 5. It is noticeable that the plate thickness increased during irradiation due to meat swelling (A and B in Fig. 5). In V6022M, the Al matrix was almost completely consumed by IL growth and pores were also formed, particularly at the interface between Al matrix and IL. R3R108 showed less IL growth and a considerable amount of Al matrix still remaining thanks to the $\mathrm{Si}$ addition in the Al matrix. This is because the Si-containing IL is believed to work as a diffusion 
barrier between $\mathrm{U}$ and $\mathrm{Al}[4-8]$.

In plate fuel, which is typically fabricated by the picture frame method [9], it is known that changes in plate dimension occur only in thickness because the other dimensions are restricted by thicker cladding [2]. Given that the as-fabricated plate is nearly flat, the bulging region in the cross section image is attributed to the meat swelling. The plate thickness increase due to meat swelling was also confirmed when the thickness of the meat region was compared with that of the non-fueled region off the left side of the meat edge (see Fig. 5). Although it is true that a small portion of the plate thickness increase originated from the so-called 'springback effect' [10], the dominant factor in the plate thickness increase was from the meat swelling. The springback effect is found during plate rolling by the picture frame method: The mechanically harder meat region pushes out more than the softer Al region. Hence, the plate thickness is slightly greater in the meat region. The plate thickness increase by this phenomenon is typically $\sim 10 \mathrm{~m}$, which is insignificant compared to $\sim 250 \mathrm{~m}$ by the meat swelling of the plates dealt with in this study.

The extensive IL growth in V6022M showed an eventual establishment of an IL network, meaning that the IL phase became the continuous phase (Fig. 6(a)). On the other hand, R3R108 showed that the Al matrix remained as the continuous phase to EOL (Fig. 6(b)).

No apparent particle sintering (or agglomeration) in the meat of V6022M was observed. This is probably due to the relatively lower U-loading and the high IL growth. However, the observation in R3R108 was quite different in that fuel particles had agglomerated because of higher fuel loading and inhomogeneous mixing of the fuel particles and matrix. Large pores were prominent in the meat of V6022M, particularly at the interface between the IL and Al matrix. The largest pores were found at the peak thickness location of the plate. These pores were formed during irradiation. This conclusion is based on the observation that porosity included during fabrication is small, such as $\sim 2 \%$ of the meat volume, but this porosity is filled up early in life by meat swelling. Hence, the pores found during PIE are believed to be formed at a later stage of irradiation by a combination of burnup and mechanical 
state of the location.

Quantification of meat swelling in dispersion fuel plates was performed by measuring meat thickness directly at every $0.5 \mathrm{~mm}$ along the width direction using an $\mathrm{OM}$ image. It is assumed that asfabricated meat thickness is uniform. The meat swelling was obtained based on the measured meat thickness data by :

$$
\left(\frac{\Delta \mathrm{V}}{\mathrm{V}_{0}}\right)_{\mathrm{m}}=\frac{\Delta \mathrm{t}_{\mathrm{m}}}{\mathrm{t}^{0}{ }_{\mathrm{m}}}
$$

where $\Delta \mathrm{t}_{\mathrm{m}}$ is the meat thickness change after irradiation, and $\mathrm{t}_{\mathrm{m}}^{0}$ is the as-fabricated meat thickness. The uncertainty in the measured meat swelling is considerable because the boundary between the meat and cladding is vague. Meat swelling measurement were made several times around a given location and then averaged. The measured meat swelling data and porosity are given in Table 2 . As can be seen in Eq. (1), the meat swelling was determined from pre- and post-irradiation meat thickness measurements. Therefore, no compensation is needed to consider the rather uncertain asfabricated plate thickness affected by the springback effect discussed above.

Porosity measurement was also made similarly. As discussed earlier, this porosity does not include the fabrication porosity that is healed by the meat swelling. Porosity measurement is carried out manually by using the point counting method [11], with an even interval of $0.5 \mathrm{~mm}$ from the meat edge to the center, at the same location where the meat swelling was measured. Since we will compare the measured data with the predictions using the analytical meat swelling model that does not consider porosity, the measured porosity was then subtracted from the measured meat swelling. The analytical meat swelling model is explained briefly in the following section.

The meat swelling for V6022M was measured for only a half-width because the meat swelling was symmetric in the width direction thanks to the flipping during irradiation, as described earlier. The meat swelling was measured for whole width of R3R108 because it had asymmetric FD distribution. 
Compared to V6022M, the FD at the hot edge side was higher in R3R108, which caused higher meat swelling.

For both plates, the measured meat swelling includes considerable uncertainties. The major source of the uncertainties is the unclear meat-cladding boundaries, and the use of the nominal as-fabricated meat thickness assuming uniform meat thickness. In addition, as discussed in previous section, the measured values are average values obtained around the interval point, which causes errors.

\section{Meat swelling model without considering creep}

During irradiation, several phenomena simultaneously take place in fuel meat that contribute meat volume increase. They are fission induced swelling in U-Mo fuel particles, chemical volume expansion by IL formation, swelling in ILs by fission products, and volume consumption in U-Mo and $\mathrm{Al}$ matrix due to IL growth.

An empirical correlation for U-Mo fuel swelling was documented by Kim [12]. The U-Mo fuel swelling is given as a function of FD as follows:

$$
\begin{array}{ll}
\left(\frac{\Delta V}{V_{0}}\right)_{f}=5.0 f_{d} & f_{d} \leq 3 \times 10^{21} \text { fission } / \mathrm{cm}^{3} \\
\left(\frac{\Delta V}{V_{0}}\right)_{f}=15+6.3\left(f_{d}-3\right)+0.33\left(f_{d}-3\right)^{2} & f_{d} \geq 3 \times 10^{21} \text { fission } / \mathrm{cm}^{3}
\end{array}
$$

where $f_{d}$ is in $10^{21}$ fission $/ \mathrm{cm}^{3}$.

IL growth is believed to cause an increase in meat volume. A time-dependent volume fraction of IL in meat needs to be modeled to evaluate volume expansion by IL growth. IL growth models by using inpile test data have been reported [13], [14]. The available IL growth model for in-pile tests is given as: 


$$
Y_{0}^{2}=2.6 \times 10^{-8} \sqrt{\dot{f}} \exp \left(-\frac{3850}{T}\right) t
$$

where $Y_{0}$ is IL thickness for pure $\mathrm{Al}$ matrix in $\mu \mathrm{m}, \dot{f}$ the fission rate in fission $/ \mathrm{cm}^{3}-\mathrm{sec}, \mathrm{T}$ the temperature in $\mathrm{K}$, and $\mathrm{t}$ the irradiation time in second.

The addition of $\mathrm{Si}$ in the $\mathrm{Al}$ matrix reduced IL thickness growth [4-8],[14]. It is also known that IL growth is dependent on the Mo content in the fuel [15]. Additional factors to consider Si and Mo effects on IL growth are multiplied to Eq. (3) as follows:

$$
Y^{2}=Y_{0}^{2} f_{S i} f_{M o}
$$

where $\mathrm{Y}$ is the IL thickness for Si-added $\mathrm{Al}$ matrix in $\mu \mathrm{m}, f_{S i}$ is the reduction factor by Si addition into the matrix, and $f_{M o}$ the Mo content factor on IL growth. Detailed explanation on these additional factors can be found in [14-17].

Kim [14] developed a model that converts the IL thickness to the IL volume in which the fuel particles are assumed to have a uniform size and distributed in an FCC array. Using the FCC model, the IL volume fractions in the meat were obtained as a function of the calculated IL thicknesses for V6022M and R3R108, as shown in Fig. 7. The empirical model that fitted with data from RERTR-4 plates is also compared with the FCC model prediction, but only the result obtained using the FCC model is given for R3R108 because no empirical correlation for U-loading other than $6 \mathrm{gU} / \mathrm{cm}^{3}$ is available.

The IL forming reaction produces a volume increase due to the low density of IL. It is expected that a newly formed IL has a larger volume than the consumed fuel volume and Al matrix volume. These consumed U-Mo and Al matrix volumes are calculated by mass conservation established between the masses of the reacted fuel and the U-Mo in the produced IL. Although the chemical volume expansion by IL growth was considered in the meat swelling calculation, the extent is very small [18]. The effect 
of the IL volume expansion is insignificant on meat creep behavior; however, the extent of IL growth can provide a possibility of the formation of an IL network in the meat, which affects creep deformation of the dispersant fuel particles. More details will be discussed later in section 6 .

By summing the fuel swelling by fission products, the volume expansion by IL growth, the swelling in IL by fission products, and the consumption of U-Mo fuel and Al volume due to IL growth, we obtain the following expression for fuel meat swelling:

$$
\left(\frac{\Delta \mathrm{V}}{\mathrm{V}_{0}}\right)_{\mathrm{m}}=\frac{\left(V_{f}+V_{A l}+V_{I L}\right) v_{f}}{V_{f}^{0}}-1
$$

where $v_{f}$ is the as-fabricated fuel volume fraction, $V_{f}$ the time dependent fuel volume, $V_{A l}$ the time dependent Al matrix volume, $V_{f}^{0}$ the as-fabricated fuel volume, and $V_{I L}$ the time dependent IL volume obtained by using FCC model. The fuel meat swelling given in Eq. (5) does not include any consideration for pore formation, creep and mass relocation. A detailed description of meat swelling modeling will be a separate publication [18].

The measured meat swelling data are plotted in Fig. 8 with the calculated by using Eq. (5) for V6022M and R3R108. While both plates show consistent results approximately beyond $5 \mathrm{~mm}$ from the meat edge, a remarkable discrepancy is visible in the meat edge region. One noticeable observation is that the area marked ' $\mathrm{A}$ ' formed above the curve by the measured and below the curve by the predicted at the edge is almost equivalent to the marked area ' $\mathrm{B}$ ' formed above the curve by the predicted and below the curve by the measured. It implies that the mass in the region A moves to region B. The amount of the peak meat swelling in R3R108 is larger than that of V6022M. It is due to the higher FD by the higher fission rate and asymmetric power peaking in this region.

\section{ABAQUS Simulation}




\subsection{Input data}

Table 3 summarized material properties and the calculation scheme for creep and swelling used as the input data for the ABAQUS simulation. The creep rate constant of U-Mo was obtained previously and documented elsewhere [2]. On the other hand, there are no available data for the creep rate constants of the IL and Al matrix. To find the best-fit creep rate constants for the IL and Al matrix, finite element analysis was performed simulating the total meat swelling and creep. The yield strength of cladding, tempered Al 6061 alloy, was increased to $280 \mathrm{MPa}$ due to irradiation hardening [2].

It is logical to assume that the creep behavior of the U-Mo particles in the dispersion meat is equal to that of the U-Mo foil case reported in [2].

It is known that the ratio of $\mathrm{Al}$ to $(\mathrm{U}+\mathrm{Mo})$ in the IL is most frequently 3 from PIE observation such as $\mathrm{U}(\mathrm{Mo}) \mathrm{Al}_{3}$ [19]. Therefore, in the absence of available mechanical properties of the IL, the data for $\mathrm{UAl}_{3}$ available from [20] were used for the IL.

The following equation was employed for the creep rate of the U-Mo fuel particles as:

$$
\dot{\varepsilon}_{c}=A_{c} \sigma \dot{f}
$$

where $\dot{\mathcal{E}}_{c}$ is the equivalent creep rate in $\mathrm{s}^{-1}, A_{c}$ the creep rate constant in $\mathrm{cm}^{3} / \mathrm{MPa}, \sigma$ the equivalent stress in MPa, and $\dot{f}$ the fission rate in fission $/ \mathrm{cm}^{3}$-sec.

\subsection{ABAQUS mesh design}

The finite element mesh model assumed that the fuel meat was composed such that single-sized U-Mo 
fuel particles were embedded in the Al matrix in an FCC array. The number of fuel particles in the meat was calculated to satisfy the known U-loading in the meat. The time-dependent evolution of the microstructure including the fuel swelling and IL growth was handled by ABAQUS. A detailed schematic for the ABAQUS mesh model of the meat cross section, particularly at one corner region of the meat edge, is shown in Fig. 9.

When the distance between two neighboring U-Mo particles is smaller than the fission fragment range, typically $7-10 \mu \mathrm{m}$, the creep rate constants of the Al matrix and IL surrounding the fuel particles were also obtained by Eq. (6). The average distance between the U-Mo particles in V6022M is around 15 $\mu \mathrm{m}$ and that in R3R108 is $7.5 \mu \mathrm{m}$ because of the different U-loadings. Since fission also occurs in the ILs, the fission induced creep is dominant in the recoil range of the Al matrix.

Although no fission occurs, fission recoil damage exists in the Al matrix. Fission damage in a mesh in the Al matrix was estimated using an inverse proportionality of the distance from the fuel surface. Since the range of an energetic fission fragment in the Al matrix is about $15 \mu \mathrm{m}$, nearly the entire $\mathrm{Al}$ matrix in both plates is affected by fission damage. Using the method reported in [23], the effective fission rate in a mesh in the $\mathrm{Al}$ matrix was approximated as one tenth of the nearest U-Mo fuel particles.

IL thickness growth was assumed to be uniform in the meat, which is justifiable because the combined effect of the fission rate and temperature is about the same on IL growth for both the meat edge and meat center region.

The fission rate for a mesh contained in the IL was calculated using the uranium concentration in the IL.

Three mesh layers with different thickness surrounding the fuel particles were considered to simulate IL growth during irradiation. The mesh thicknesses in the case of V6022M were $7 \mu \mathrm{m}, 8 \mu \mathrm{m}$, and 3 $\mu \mathrm{m}$ for the inner, intermediate, and outer meshes, respectively. A much finer mesh design was employed at the meat-cladding interface for more accurate analyses (see inset in Fig. 9). 
Transformation of the Al matrix to an IL was realized by assigning different field variables to the layers at each analysis step. Specifically, when a mesh originally assigned as a part of the Al matrix became an IL, the properties of the IL were assigned after transformation with the previous state of stresses and strains from the $\mathrm{Al}$ matrix.

A generalized plane strain assumption was adopted for the FEA modeling because the plate length was much larger than any other dimensions, which justifies that the strain in a plane is constant. Element type CPEG8R that is an 8-node biquadratic quadrilateral with reduced integration was applied. A geometrical nonlinearity was also used to take plasticity and large deformation into account for more precise analysis.

Fig. 10 shows the evolution of the IL of V6022M for the ABAQUS analysis. The test duration was divided into four sections considering IL thickness increase.

The meat true strain was derived from the meat swelling as follows:

$$
\varepsilon_{\text {sw,true }}=\ln \left(1+\left(\frac{\Delta V}{V_{0}}\right)_{m}\right)
$$

The total meat swelling, $\left(\frac{\Delta V}{V_{0}}\right)_{m}$ is given by Eq. (5).

\subsection{ABAQUS Simulation results}

In the fuel meat, stresses are generated by the fission induced fuel meat swelling. These stresses must be relieved by U-Mo fuel creep and mass relocation of constituents in the meat to avoid buckling. The creep and mass relocation of the meat rely chiefly on the continuous phase. Based on PIE observations in which the continuous phase was the IL for V6022M, and the Al matrix for R3R108, it is reasonable to find the creep rate constant for IL $\left(\mathrm{A}_{\mathrm{IL}}\right)$ by the best-fit result obtained from V6022M. 
In the same context, the creep rate constant for the $\mathrm{Al}$ matrix $\left(\mathrm{A}_{\mathrm{Al}}\right)$ is found by the best-fit result of R3R108. The time when the IL becomes continuous is important because the creep of the continuous phase is likely to determine the extent of the mass relocation. For V6022M, the IL became the continuous phase at 75 EFPD, and remained so for the rest of test (182 EFPD). This rapid evolution in the IL growth allows us to consider that the IL was the continuous phase to determine creep behavior of V6022M. However, the creep rate constant for the IL is probably underpredicted by this assumption.

The creep rate constant for U-Mo monolithic fuel $\left(\mathrm{A}_{\mathrm{U}-\mathrm{Mo}}\right)$ available in the literature [2] was used for the U-Mo fuel particles. Fitting the creep rate constants of the IL and Al matrix simultaneously in the V6022M analysis was complicated because the continuous phase changed during irradiation. We observed that the continuous phase dominantly determined the extent of mass relocation. To overcome this complexity, we first estimated the creep rate constant for the Al matrix using R3R108 in which the $\mathrm{Al}$ matrix remained as the continuous phase throughout the irradiation. The creep rate constant for the IL was then estimated using the V6022M analysis with known creep rate constants for the U-Mo particles and Al matrix. This procedure was repeated until the best fit was obtained. The measures for the best fit in the ABAQUS simulation were the measured meat swelling and the extent of the fuel particle deformation.

\subsubsection{Creep rate constant for Al matrix.}

ABAQUS simulations were performed by varying the creep rate constant for the Al matrix in R3R108. The creep rate constants of the U-Mo fuel and IL were set at 500 and $400 \times 10^{-25} \mathrm{~cm}^{3} / \mathrm{MPa}$, respectively. The best fit of the measured meat swelling was obtained when the creep rate constant of the Al matrix was $50 \times 10^{-25} \mathrm{~cm}^{3} / \mathrm{MPa}$ (Fig. 11). When the constant was set larger than $100 \times 10^{-25}$ $\mathrm{cm}^{3} / \mathrm{MPa}$, the discrepancy in the meat swelling between the simulation result and the measured 
became larger.

\subsubsection{Creep rate constant for IL}

ABAQUS simulations were made for several values of the creep rate constant for the IL by fixing the creep rate constant of the $\mathrm{Al}$ matrix at $50 \times 10^{-25} \mathrm{~cm}^{3} / \mathrm{MPa}$ as shown in Fig. 12. The best simulation result was obtained when the creep rate constant of the IL was $400 \times 10^{-25} \mathrm{~cm}^{3} / \mathrm{MPa}$. Although small difference from the case with $400 \times 10^{-25} \mathrm{~cm}^{3} / \mathrm{MPa}$, the case with $700 \times 10^{-25} \mathrm{~cm}^{3} / \mathrm{MPa}$ was considered to be an overprediction. This suggests that the obtained creep rate constant entails considerable uncertainty.

\subsubsection{Stress calculation}

Fig. 13 shows the Von Mises stress of the fuel particles located at the meat-cladding interface at different irradiation times. The stress at the meat edge becomes zero because the stress-free boundary condition was applied. The local maxima and minima of the stress are repeated. This repetition was believed to be due to the modeling scheme that the fuel particles are distributed in a regular array. The local apices occurred at the interface between the fuel particle and continuous phase. The stresses within the fuel particles appeared to be mitigated by the deformation of the continuous phase. The most severe fuel particle deformation was observed at the peak meat thickness location as the magnitude of the stress becomes largest.

At the hot side bulge location, R3R108 showed a higher equivalent stress of the fuel particles than V6022M due to the higher meat swelling. The Von Mises stresses of the continuous phase at the 
bulge regions of V6022M and R3R108 are compared in Fig. 14. The stress of the continuous phase was also noticeably higher at the meat-cladding interface in R3R108. The stresses built up in the region were not effectively relieved by creep due to the low creep rate in the continuous phase or the Al matrix. Consequently, more deformation occurred in the fuel particles. On the other hand, less deformation in fuel particles was observed in V6022M because the higher creeping IL was the continuous phase for the majority of time. The U-Mo fuel particles with less deformation were relocated through the continuous phase.

Fig. 15 shows a contour of the creep strain magnitude caused by the meat swelling and mass relocation. It appears that the stresses induced by the meat swelling at the edge was effectively transferred towards the width center, relocating the meat mass to the region where the peak meat thickness was measured. It is noticeable that the magnitude of the creep strain of the fuel particles is higher for R3R108 than that for V6022M. The fuel particles in V6022M showed less creep because they were surrounded with a thicker IL than those in R3R108. The life-averaged fission rate of R3R108 at this region was higher by about a factor of three compared to V6022M. Hence, R3R108 showed more fuel particle creep occurred by combination of the higher fission rate and stress, which leads to a more severe particle elongation through the soft $\mathrm{Al}$ matrix with plasticity.

Fig. 16 shows a comparison of the extent of fuel particle deformation at the hot side bulge region for V6022M and R3R108 at EOL. Fuel particle deformation indicated by the extent of elongation toward the meat transverse center is more severe for R3R018 as mentioned earlier. The local stresses combined with the creep within the fuel particles cause more particle deformation when the surrounding material does not accommodate mass relocation. In this sense, it is deducible that the more deformation of the fuel particles is due to the high stresses and creep while the thin IL provides a local deformation, but the overall mass relocation was restrained by the $\mathrm{Al}$ matrix that has a lower creep rate. 


\section{Discussion}

Deformation in the fuel particles appeared to be determined by the creep of the fuel particles. It is also likely to be affected by the continuous phase that surrounds the fuel particles. The Al matrix is the continuous phase typically during the early irradiation stages. As the IL grows, it surrounds the fuel particles but covers only the surface of the isolated fuel particles. When the extent of IL growth is large enough to form a network of IL, the IL becomes the continuous phase. In a highly loaded fuel meat, the fuel particles can come into contact locally among themselves, where the fuel particles behave like a continuous phase. This statement is particularly valid when the fuel particles sinter together.

The effect of the continuous phase on the mass relocation is significant. From the ABAQUS simulations, we have frequently observed that the fuel particles show negligible deformation when the continuous phase was set with a nil creep rate constant. Several ABAQUS simulations were performed to investigate the effect of the creep rate constant of the U-Mo fuel particles on creep and mass relocation of the fuel meat of R3R018 as shown in Fig. 17. No significant change in creep and mass relocation was discernable by the creep rate constant of the U-Mo fuel between 400 and $700 \mathrm{x}$ $10^{-25} \mathrm{~cm}^{3} / \mathrm{MPa}$, suggesting that the U-Mo creep had negligible influences on the creep and mass relocation of the meat.

The effect of the creep rate of the Al matrix was examined using V6022M. It should be noted that the IL became the continuous phase in V6022M at 75 irradiation days with $15 \mu \mathrm{m}$ of thickness, implying that the IL was the continuous phase for the next 180 days. Fig. 18(a) shows a comparison of several creep rate constants of the $\mathrm{Al}$ matrix in $\mathrm{V} 6022 \mathrm{M}$. The peak meat thickness location was insensitive to the creep rate constant of the $\mathrm{Al}$ matrix. We also examined the effect of the creep rate constant of the IL in R3R108 where the IL was the discontinuous phase during the whole irradiation duration, and the results are shown in Fig. 18(b). It turned out to be that the peak-meat-thickness location was also 
insensitive to the creep rate constant of the IL. Analysis results showed that the extent of the fuel particle deformation and mass relocation was determined predominantly by the creep of the continuous phase.

Because the IL is predominantly composed of $\mathrm{Al}$, one may suspect that its creep rate constant may be closer to that of the $\mathrm{Al}, 50 \times 10^{-25} \mathrm{~cm}^{3} / \mathrm{MPa}$, than to that of the U-Mo, $500 \times 10^{-25} \mathrm{~cm}^{3} / \mathrm{MPa}$. Therefore, the simulation result that the creep rate constant of the IL is in fact closer to that of the U-Mo is counterintuitive. The only possible explanation would be that the IL is amorphous whereas Al is crystalline during irradiation [24]. An amorphous material generally shows a higher fluidity than a crystalline material [25],[26]. Hence, a higher creep rate is expected. However, we did not attempt to examine this effect of amorphization in detail, as it is beyond the scope of the present study.

Although the argument that the creep rate constants may vary with burnup appears to be more realistic because the material properties change by burnup, we used constant values for the simulations for simplicity. Therefore, the creep rate constants obtained in this study are considered to be effective values representing the specific irradiation conditions.

Since the creep rate constants for the Al matrix and IL were obtained by data fitting with the measured meat swelling, these results should also contain uncertainties. However, the consistent ABAQUS simulations with the measured data for both plates using the creep rate constants for the IL and $\mathrm{Al}$ matrix confirm that creep is the main underlying mechanism for the mass relocation of the meat and fuel particle deformation.

The major stresses generated at the meat edge region were in the direction toward the meat center to push the neighboring particles through the continuous phase (IL or Al matrix) due to the constraint provided by the cladding. It resulted in deformation of the fuel particles, particularly at the region near the meat-cladding interface.

The strain in the fuel particles was determined by the stress state between the fuel particles and the surrounding material. Under the same irradiation condition, less deformation in the U-Mo fuel 
particles occurred when the IL was the continuous phase in the meat than when the Al matrix was the continuous phase, as the IL had a higher mechanical strength than the Al matrix in the ABAQUS simulation. However, when the IL was the continuous phase, a higher meat mass relocation toward the center region took place since the IL had a higher creep rate than the Al matrix.

The stresses at the meat-cladding interface were higher than those at the meat center in the thickness direction. This probably originated from the assumption that the cladding was free of creep. The high stresses can cause debonding between the meat and cladding, reported in [27], particularly at a location where the sign of the shear stress in the meat is the opposite of that in the cladding.

From the safety standpoint, the formation of a bulge location by the meat mass relocation is a concern because the increased fuel volume may build up a hot spot, resulting in a peak fuel temperature at that spot. An additional meat volume increase by about $10 \%$ point in $\mathrm{V} 6022 \mathrm{M}$ and $15 \%$ point in R3R108 must be considered for a hot spot calculation.

By relieving the stresses induced by the fuel meat swelling, creep in the meat allows U-Mo/Al dispersion fuel to achieve high burnup without buckling in the plate. Fuel particle transversal elongation at the meat end and particle sintering were observed in RERTR-9 test plates [28] as shown in Fig. 19, which might be due to the high fuel loading and high fission rate. The morphology of the fuel particle elongation clearly shows how the fuel particles behaved under the stress and creep condition. The U-Mo fuel particle distribution in the meat was modeled as an FCC array in ABAQUS FEA simulations with no consideration of the particle agglomeration. In reality, however, U-Mo particles may locally become the continuous phase by the fuel particle coagulation caused by the inhomogeneous distribution of the fuel particles in the matrix and mechanical deformation of the meat during the irradiation (see Fig. 19). Based on the observation that the pre-irradiation fuel particles after plate fuel fabrication are typically spherical [29],[30], this severe fuel particle deformation appears to be caused by fission induced meat swelling and creep. As U-Mo fuel becomes continuous in the meat as the U-loading increases, it is expected that the peak meat swelling location moves more 
to the width center, similar to the monolithic cases reported in [2].

Thermal creep was not considered in the ABAQUS simulation in the present study since the temperature range of the plates analyzed in this work was $90-145{ }^{\circ} \mathrm{C}$. This low and narrow temperature range is the prerequisite for athermal creep. Based on data [31-34], the creep rate of Al by neutron irradiation was about an order of magnitude lower than the fission-induced creep rate. Hence, neither the thermal nor neutron irradiation creep was considered. Although there is no fission in the Al matrix, the enhancement by recoiling damage may be responsible to explain the creep rate for the $\mathrm{Al}$ matrix.

Silicon addition in the Al matrix is beneficial because of the reduction in IL growth. On the other hand, it is undesirable because the reduced IL growth may also reduce stress relaxation by the creep mechanism of the meat or the meat mass relocation to the width center. This was attributed to the fact that the meat mass relocation beyond the bulge location was low because the Al matrix that had a lower creep rate remained as the continuous phase in the meat. Silicon addition into the Al matrix may have influences on both irradiation hardening and thermal softening of the Al matrix and cladding. The irradiation hardening by neutron irradiation should be greater in the cladding that contains $\sim 1 \mathrm{wt} . \% \mathrm{Mg}$ and $0.8 \mathrm{wt} . \% \mathrm{Si}$ whereas $\mathrm{Mg}$ is not intentionally added in the Al matrix. $\mathrm{Mg}$ is known to form $\mathrm{Mg}_{2} \mathrm{Si}$ precipitates that contribute to increase the hardness of the $\mathrm{Al}$ alloy during irradiation [35],[36]. However, in the matrix devoid of $\mathrm{Mg}$, the population of this precipitate is probably low. Hence, the irradiation hardening may be negligible in the Al matrix. This can explain the consistent simulation results for both V6022M and R3R108 that were obtained using the same creep rate constant, although much different Si contents (no Si in V6022M and 5 wt.\% Si in R3R108) were used in the simulations. In other words, the presence of $\mathrm{Si}$ in the $\mathrm{Al}$ matrix in the content range dealt with in this study has a negligible effect on the creep rate of the Al matrix. However, a further study may be necessary to investigate more thoroughly the effect of $\mathrm{Si}$ addition in the $\mathrm{Al}$ matrix on creep and mass relocation in the meat. 
Thermal softening in the cladding was neglected for both plates in this study because the peak cladding temperatures were much lower (lower than $100^{\circ} \mathrm{C}$ ) than the temperature regime (higher than $160{ }^{\circ} \mathrm{C}$ ) in which thermal softening by dissolution of the $\mathrm{Mg}_{2} \mathrm{Si}$ precipitates [37] must be considered.

\section{Conclusions}

The mass transport in the U-Mo/Al dispersion meat in fuel plates observed at the meat end region was studied for two uniquely different fuel plates: One with a pure Al matrix and long irradiation, the other with $5 \mathrm{wt} . \% \mathrm{Si}$ in the Al matrix and shorter irradiation. The latter has a greater fission rate.

An ABAQUS FEA package with a user-subroutine was employed to simulate the meat swelling, creep, and mass relocation in the U-Mo/Al dispersion meat. The ABAQUS modeling included models such as fission induced fuel swelling, interaction layer (IL) volume change, and fuel and Al matrix consumption by IL growth. The simulation results in terms of fuel meat swelling were consistent with the measured data. The best fit was found when the creep rate constants were set at $400 \times 10^{-25}$ $\mathrm{cm}^{3} / \mathrm{MPa}$ for the IL and $50 \times 10^{-25} \mathrm{~cm}^{3} / \mathrm{MPa}$ for the Al matrix, respectively, fixing the creep rate constant of the U-Mo at $500 \times 10^{-25} \mathrm{~cm}^{3} / \mathrm{MPa}$. These values are considered valid for both the pure Al matrix and Al-5Si matrix. The obtained creep rate constants are considered as effective values optimized for the irradiation and materials condition dealt with in this study.

The stresses caused by meat swelling were mitigated by the creep of a continuous phase. These stresses are believed to force the meat mass to move from the meat end region toward the transversal center by the creep deformation of the continuous phase.

Depending on the creep rate of the continuous phase, fuel particle deformation and mass relocation were determined. The Al matrix was the continuous phase at early stage of irradiation, but the IL phase took over to be the continuous phase in a high IL growth plate (V6022M). Because the IL had a 
higher creep rate than the Al matrix, more mass relocation was observed in V6022M. Contrarily, higher fuel particle deformation but less mass relocation occurred in R3R108 because the less creeping Al matrix was the continuous phase.

The Si addition in the Al matrix was effective and beneficial in suppressing IL growth. However, reduced IL growth may be disadvantageous considering the increased buckling probability by restricted mass relocation in the meat is an effective way to relieve stress. The extent of creep and mass relocation with $\mathrm{Si}$ addition is needed to be investigated in future studies when more data are available.

\section{Acknowledgements}

The test plates used in this work irradiated at the ATR (Advanced Test Reactor) in the GTRI Conversion program (formerly known as the RERTR program). There have been many contributors for the irradiation tests and post irradiation examination. In this regard, Drs. G.L. Hofman of ANL, and D.M. Wachs, M.K. Meyer, and A.B. Robinson of INL are acknowledged. Dr. J.S. Cheon of KAERI is acknowledged for helping in the use of ABAQUS.

This work was supported by the National Research Foundation of Korea (NRF) grant funded by the Korean government (Ministry of Education, Science and Technology) (No. 2011-0031771), and in part by the U.S. Department of Energy, Material Management and Minimization (NA-23) Reactor Conversion Program, under Contract No. DE-AC-02-06C H11357 between UChicago Argonne, LLC and the Department of Energy for the ANL contribution. 


\section{References}

[1] G.L. Hofman, Yeon Soo Kim, A.B. Robinson, Trans. Research Reactor Fuel Management (RRFM), ENS, Vienna, Austria, Mar. 22-25, 2009.

[2] Yeon Soo Kim, G.L. Hofman, J.S. Cheon, A.B. Robinson, D.M. Wachs, J. Nucl. Mater., 437 (2013) 37 .

[3] ABAQUS Analysis User's Manual, Dassault Systems, 2013.

[4] Yeon Soo Kim, Proc. Int. Meeting on Reduced Enrichment for Research and Test Reactors (RERTR), Boston, USA, Nov. 6-10, 2005.

[5] A. Leenaers, C. Detavernier, S. Van den Berghe, J. Nucl. Maters., 381 (2008) 242.

[6] E. Perez, B. Yao, Y.H. Sohn, Proc. Int. Meeting on Reduced Enrichment for Research and Test Reactors (RERTR), Beijing, China, Nov. 1-5, 2009.

[7] J.M. Park et al, Trans. Research Reactor Fuel Management (RRFM), ENS, Hamburg, Germany, Mar 2-5, 2008.

[8] D.D. Keiser, A.B. Robinson, J.F. Jue, P. Medvedev, D.M. Wachs, M.R. Finlay, J. Nucl. Mater., 393 (2009) 311.

[9] Yeon Soo Kim, Uranium intermetallic fuels (U-Al, U-Si, U-Mo), in: R.J.M. Konings (Ed.), Comprehensive Nuclear Materials, vol. 3, pp. 391 - 422, Elsevier, Amsterdam, 2012.

[10] Van den Berghe, Y. Parthoens, G. Cornelis, A. Leenaers, E. Koonen, V. Kuzminov, C. Detavernier, J. Nucl. Maters., 442 (2013) 60.

[11] R.T. DeHoff, F.N. Rhines, McGraw-Hill, New York, 1968.

[12] Yeon Soo Kim, G. Hofman, J. Nucl. Mater., 419 (2011) 291.

[13] D.M. Wachs, D.E. Burkes, S.L. Hayes, W. Skerjanc, G.L.Hofman, Yeon Soo Kim, H.J. Ryu, Proc. Int. Meeting on Reduced Enrichment for Research and Test Reactors (RERTR), Cape Town, South Africa, Oct.29 - Nov. 2, 2006.

[14] Yeon Soo Kim, G.L. Hofman, H.J. Ryu, J.M. Park, A.B. Robinson, D.M. Wachs, Nucl. Eng. 
Technol., 45 (7) (2013) 827.

[15] J.M. Park, H. Ryu, G. Lee, H. Kim, Y. Lee, C. Kim, Yeon Soo Kim, G.L. Hofman, Proc. Int. Meeting on Reduced Enrichment for Research and Test Reactors (RERTR), Boston, USA, Nov. 6-10, 2005.

[16] S.L. Hayes, G.L. Hofman, M.K. Meyer, J. Rest, J.L. Snelgrove, Proc. Internat. Meeting Reduced Enrichment for Research and Test Reactors (RERTR), Bariloche, Argentina, November 3-8, 2002

[17] Yeon Soo Kim, G. Hofman, ANL/RERTR/TM-11-24, Argonne National Laboratory, 2011.

[18] Yeon Soo Kim, G.Y. Jeong, J.M. Park, A.B. Robinson, J. Nucl. Mater., 465 (2015) 142.

[19] Ho Jin Ryu et al, J. Phase. Equil. Diff., 27(6) (2006) 651.

[20] S.Y. Kang, T. Gao, X.F. Tian, Physica B: Cond. Matter, 407 (2012) 748.

[21] Z.G. Mei, Private communication, Argonne National Laboratory, 2014.

[22] J.R. Davis, ASM International, Metals Park, Ohio, 1990.

[23] Yeon Soo Kim, G.L. Hofman, H.J. Ryu, S.L Hayes, J. Phase Equil. Diff., 27 (2006) 614.

[24] H.J. Ryu, Yeon Soo Kim, G.L. Hofman, J. Nucl. Mater., 385 (2009) 623.

[25] S. Klaumunzer, Rad. Effect Defects Solid, 110 (1989) 79.

[26] G.S. Grest, M.H. Cohen, I. Prigogine, S.A, Price, Eds., p.469, John Wiley and Sons, New York, 1981.

[27] A. Languille et al, Trans. RRFM, ENS, Ghent, Belgium, March 17-20, 2002.

[28] G.L. Hofman, Yeon Soo Kim, J. Rest, T. Totev, A.B. Robinson, Proc. Int. Meeting on Reduced Enrichment for Research and Test Reactors (RERTR), Washinton, D.C., USA, October 59,2008

[29] H.J. Ryu, C.K. Kim, M.S. Sim, J.M. Park, J.H. Lee, Nucl. Eng. Technol., 45 (2013) 979.

[30] C. Jarousee, G. Bourdat, M. Ripert, P. Boulcourt, P. Lemoine, Trans. Research Reactor Fuel Management (RRFM), ENS, Hamburg, Germany, Mar 2-5, 2008.

[31] E. Aitkhozhin, E. Chumakov, J. Nucl. Mater., 233 (1996) 537. 
[32] J. G. Harper, L. A. Shepard, J. E. Dorn, Acta Metal., 6 (1958) 509.

[33] N. Hu, D. Gelles, F. Garner, C. Henager Jr., N. Igata, ASTM, STP, 956 (1987) 83.

[34] E. Jones, W. Munro, N. Hancock, J. Nucl. Energy, 1 (1954) 76.

[35] A. Jostsons, R. King, Scripta Metal., 6 (1972) 447.

[36] R. King, A. Jostsons, Metal. Trans. A, 6 (1975) 863.

[37] K. Farrell, ORNL/TM-99-208, Oak Ridge National Laboratory, 1999. 


\section{Table captions}

Table 1 Irradiation test parameters of analyzed plates in the study.

Table 2 Measured meat swelling (\%), and porosity (\%) for V6022M and R3R108 plates.

Table 3 Material properties used in ABAQUS simulations. 


\section{Figure captions}

Fig. 1 Schematic of the as-fabricated cross sections at axial center plane of (a) monolithic and (b) dispersion miniplates.

Fig. 2 Fission density distributions in transverse direction in the meat at end of life (EOL).

Fig. 3 Fission rate histories at the meat axial and transverse center.

Fig. 4 Schematic illustrating PIE location of test plates.

Fig. $5 \mathrm{OM}$ images of cross-sections taken at PIE of two plates. The darkest particles are UMo fuel, the brightest is the $\mathrm{Al}$ matrix, and the gray phase in between is IL. The arrows marked by $\mathrm{A}$ and $\mathrm{B}$ show the peak plate thicknesses.

Fig. 6 Schematics illustrating the difference in microstructure between the plates at their peak plate thickness locations. The network of ILs is the continuous phase for V6022M, whereas the Al matrix is the continuous phase for R3R108.

Fig. $7 \mathrm{IL}$ volume fractions as a function of IL thickness for plates with $6 \mathrm{gU} / \mathrm{cm}^{3}$ and 8 $\mathrm{gU} / \mathrm{cm}^{3}$ uranium loadings form the RERTR-4 and RERTR-9 test campaigns.

Fig. 8 Comparison between the measured and predicted swelling.

Fig. 9 (a) Schematics of fuel plate cross section and mesh configuration for finite element modeling of (b) V6022M and (c) R3R108.

Fig. 10 Evolution of interaction layer growth at different irradiation times for V6022M.

Fig. 11 Comparison of the measured meat swelling, the calculated meat swelling and ABAQUS simulation with different Al creep rates for R3R108 plate.

Fig. 12 Comparison of the measured meat swelling, the calculated and ABAQUS simulations with different creep rates constant of IL for V6022M plate.

Fig. 13 Von Mises stress for fuel particles corresponding to the creep rate constants of IL and $\mathrm{Al}$ matrix $\left(\mathrm{A}_{\mathrm{IL}}=400 \times 10^{-25} \mathrm{~cm}^{3} / \mathrm{MPa}, \mathrm{A}_{\mathrm{Al}}=50 \times 10^{-25} \mathrm{~cm}^{3} / \mathrm{MPa}\right)$.

Fig. 14 Contour of the equivalent stress by meat swelling in the region of the peak meat 
thickness location.

Fig. 15 Contour of meat volume expansion by meat swelling and creep induced mass relocation from the meat edge to the peak meat thickness region.

Fig. 16 Comparison of fuel particle deformation in the peak meat thickness location at the end of life.

Fig. 17 Effect of the creep rate constant of the U-Mo fuel particles in R3R108. The creep rate constants of the $\mathrm{Al}$ matrix $\left(\mathrm{A}_{\mathrm{Al}}\right)$ and $\operatorname{IL}\left(\mathrm{A}_{\mathrm{IL}}\right)$ were set at $50 \times 10^{-25} \mathrm{~cm}^{3} / \mathrm{MPa}$ and $400 \mathrm{x}$ $10^{-25} \mathrm{~cm}^{3} / \mathrm{MPa}$, respectively.

Fig. 18 Effect of the creep rate constant of (a) Al matrix in V6022M and (b) IL in R3R108. Fig. $19 \mathrm{OM}$ of the fuel meat end region of RERTR-9 plate (R6R018). The fission density in U-Mo particle is $\sim 10 \times 10^{21} \mathrm{f} / \mathrm{cm}^{3}$. 
Table 1 Irradiation test parameters of analyzed plates in the study.

\begin{tabular}{|c|c|c|c|c|c|c|c|c|}
\hline \multirow[t]{2}{*}{ Plate ID } & \multirow[t]{2}{*}{ Fuel Type } & \multirow[t]{2}{*}{$\begin{array}{l}\text { Meat U } \\
\text { density } \\
\left(\mathrm{gU} / \mathrm{cm}^{3}\right)\end{array}$} & \multirow{2}{*}{$\begin{array}{l}\text { Meat } \\
\text { average } \\
\text { BU } \\
\text { (\%LEU } \\
\text { Equiv.) }\end{array}$} & \multirow[t]{2}{*}{$\begin{array}{l}\text { Time } \\
\text { (EFPD) }\end{array}$} & \multirow[t]{2}{*}{$\begin{array}{l}\text { Average } \\
\text { particle } \\
\text { size ( } \mathrm{m})\end{array}$} & \multicolumn{2}{|c|}{$\begin{array}{l}\text { Fission } \\
\text { density } \\
\left(10^{21} \mathrm{f} / \mathrm{cm}^{3}\right. \\
\text { fuel })\end{array}$} & \multirow{2}{*}{$\begin{array}{l}\text { Peak } \\
\text { plate } \\
\text { thickness } \\
\text { location } \\
(\mathrm{mm})^{*}\end{array}$} \\
\hline & & & & & & $\begin{array}{l}\text { At } \\
\text { hot } \\
\text { side }\end{array}$ & $\begin{array}{l}\text { At } \\
\text { cold } \\
\text { side }\end{array}$ & \\
\hline V6022M & $\begin{array}{c}\mathrm{U}-10 \mathrm{Mo} / \\
\mathrm{Al}\end{array}$ & 6 & 78 & 257 & 50 & 5.5 & 5.5 & 2.5 \\
\hline R3R108 & $\begin{array}{c}\mathrm{U}-7 \mathrm{Mo} / \\
\mathrm{Al}-5 \mathrm{Si}\end{array}$ & 8 & 64 & 98 & 50 & 5.5 & 3.1 & 2.0 \\
\hline
\end{tabular}

*measured from the hot side meat edge. 
Table 2 Measured meat swelling (\%), and porosity (\%) for V6022M and R3R108 plates.

\begin{tabular}{|c|c|c|c|c|c|c|c|c|c|c|c|c|c|c|c|c|c|c|c|c|c|c|}
\hline \multirow{2}{*}{ V6022M } & $\begin{array}{l}\text { Distance from } \\
\text { meat edge }(\mathrm{mm})\end{array}$ & 0 & 0.5 & & 1.5 & 2 & 2.5 & 3 & 3.5 & 4 & 4.5 & 5 & 5.5 & 6 & 6.5 & 7 & 7.5 & 8 & 8.5 & 9 & 9.5 & 10 \\
\hline & $\begin{array}{l}\mathrm{M} \\
\mathrm{P}\end{array}$ & 0 & 8.1 & 15.8 & 23.6 & 29.9 & $\begin{array}{l}33.4 \\
2.6\end{array}$ & $\begin{array}{l}38.3 \\
9.5\end{array}$ & $\begin{array}{l}36.2 \\
9.2\end{array}$ & $\begin{array}{l}30.9 \\
7.6\end{array}$ & $\begin{array}{l}26.0 \\
6.0\end{array}$ & $\begin{array}{l}22.6 \\
4.1\end{array}$ & $\begin{array}{l}21.8 \\
2.7\end{array}$ & $\begin{array}{l}20.1 \\
1.6\end{array}$ & $\begin{array}{l}21.1 \\
1.7\end{array}$ & $\begin{array}{l}18.6 \\
0.5\end{array}$ & 17.5 & 17.9 & 16.9 & 17.2 & 16.4 & 15.6 \\
\hline \multirow{4}{*}{ R3R108 } & $\begin{array}{l}\text { Distance from } \\
\text { meat edge }(\mathrm{mm})\end{array}$ & 0 & 0.5 & 1 & 1.5 & 2 & 2.5 & 3 & 3.5 & 4 & 4.5 & 5 & 5.5 & 6 & 6.5 & 7 & 7.5 & 8 & 8.5 & 9 & 9.5 & 10 \\
\hline & $\begin{array}{l}\mathrm{M} \\
\mathrm{P}\end{array}$ & 3.0 & 18.7 & 21.9 & 30.8 & $\begin{array}{l}38.3 \\
2.9\end{array}$ & $\begin{array}{l}31.9 \\
0.9\end{array}$ & 26.6 & 18.6 & 17.4 & 14.0 & 12.5 & 13.3 & 12.8 & 12.6 & 12.6 & 14.5 & 16.0 & 16.6 & 14.3 & 11.3 & $\begin{array}{l}9.6 \\
1.3\end{array}$ \\
\hline & $\begin{array}{l}\text { Distance from } \\
\text { meat edge }(\mathrm{mm})\end{array}$ & 10.5 & 11 & 11.5 & 12 & 12.5 & 13 & 13.5 & 14 & 14.5 & 15 & 15.5 & 16 & 16.5 & 17 & 17.5 & 18 & 18.5 & & & & \\
\hline & $\begin{array}{l}\mathrm{M} \\
\mathrm{P}\end{array}$ & 7.1 & $\begin{array}{l}9.9 \\
0.6\end{array}$ & 8.5 & 14.3 & 9.1 & 13.2 & 8.7 & 10.9 & 11.8 & 8.9 & 10.4 & 12.1 & $\begin{array}{l}12.1 \\
1.3\end{array}$ & 11.7 & 11.7 & 11.3 & 0.2 & & & & \\
\hline
\end{tabular}

M : Measured meat swelling.

$\mathrm{P}:$ Measured porosity. 
Table 3 Material properties used in ABAQUS simulations.

\begin{tabular}{|c|c|c|c|c|}
\hline & $\begin{array}{c}\text { Elastic constant } \\
(\mathrm{GPa})\end{array}$ & Poisson's ratio & $\begin{array}{c}\text { Creep rate constant } \\
\left(10^{-25} \mathrm{~cm}^{3} / \mathrm{Mpa}\right)\end{array}$ & Reference \\
\hline Al 6061 Cladding & 66 & 0.34 & - & {$[2]$} \\
\hline U-Mo particle & 85 & 0.34 & $\mathrm{~A}_{\mathrm{U}-\mathrm{Mo}}=500$ & {$[2]$} \\
\hline $\begin{array}{c}\text { Interaction layer } \\
* \text { Assumed to be } \\
\text { same to UAl }\end{array}$ & 134 & 0.241 & $\mathrm{ND}$ & $\begin{array}{c}\text { Elastic constant } \\
\text { and Poisson's } \\
\text { Ratio from } \\
{[20],[21]}\end{array}$ \\
\hline Al 1060 Matrix & 63 & 0.33 & $\mathrm{ND}$ & {$[22]$} \\
\hline
\end{tabular}

ND : Numerically determined by ABAQUS simulation. 


\section{Figures}

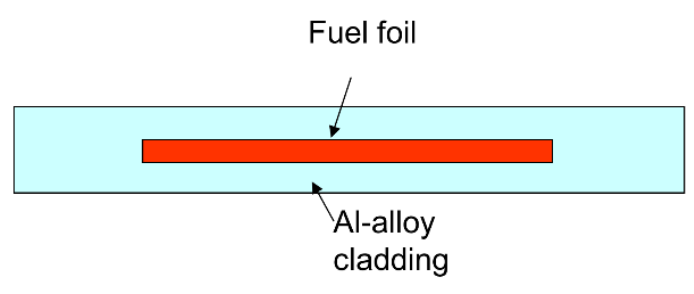

(a) Monolithic fuel form

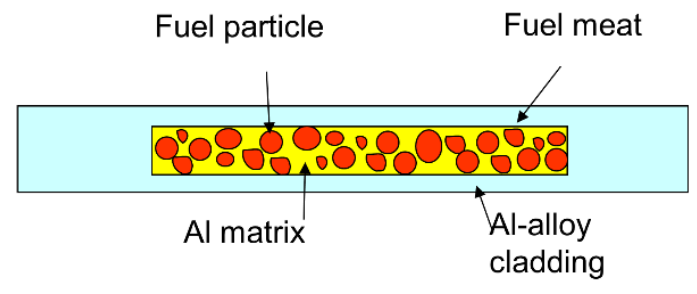

(b) Dispersion fuel form

Fig. 1 Schematic of the as-fabricated cross sections at axial center plane of (a) monolithic and (b) dispersion miniplates. 


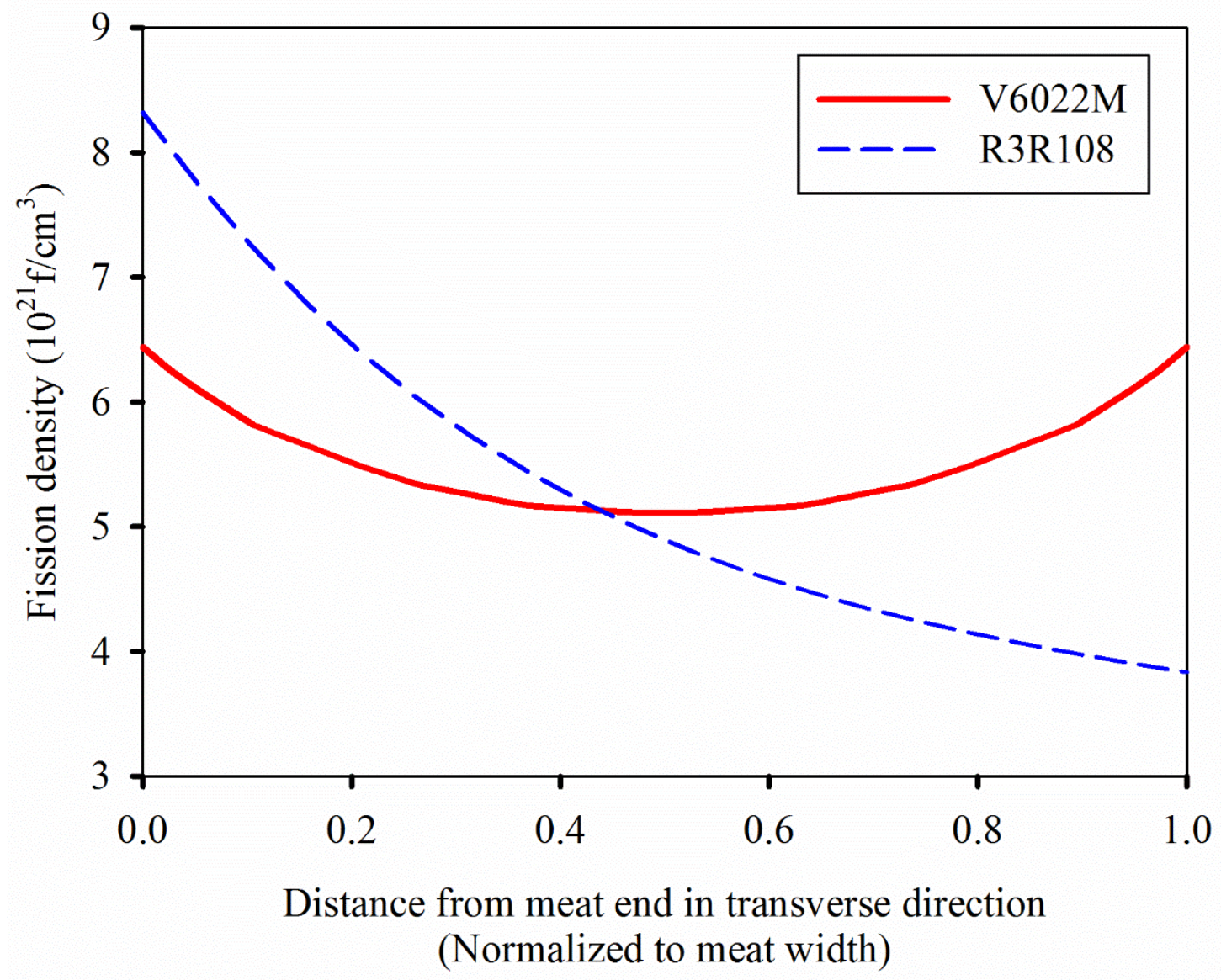

Fig. 2 Fission density distributions in transverse direction in the meat at end of life (EOL). 


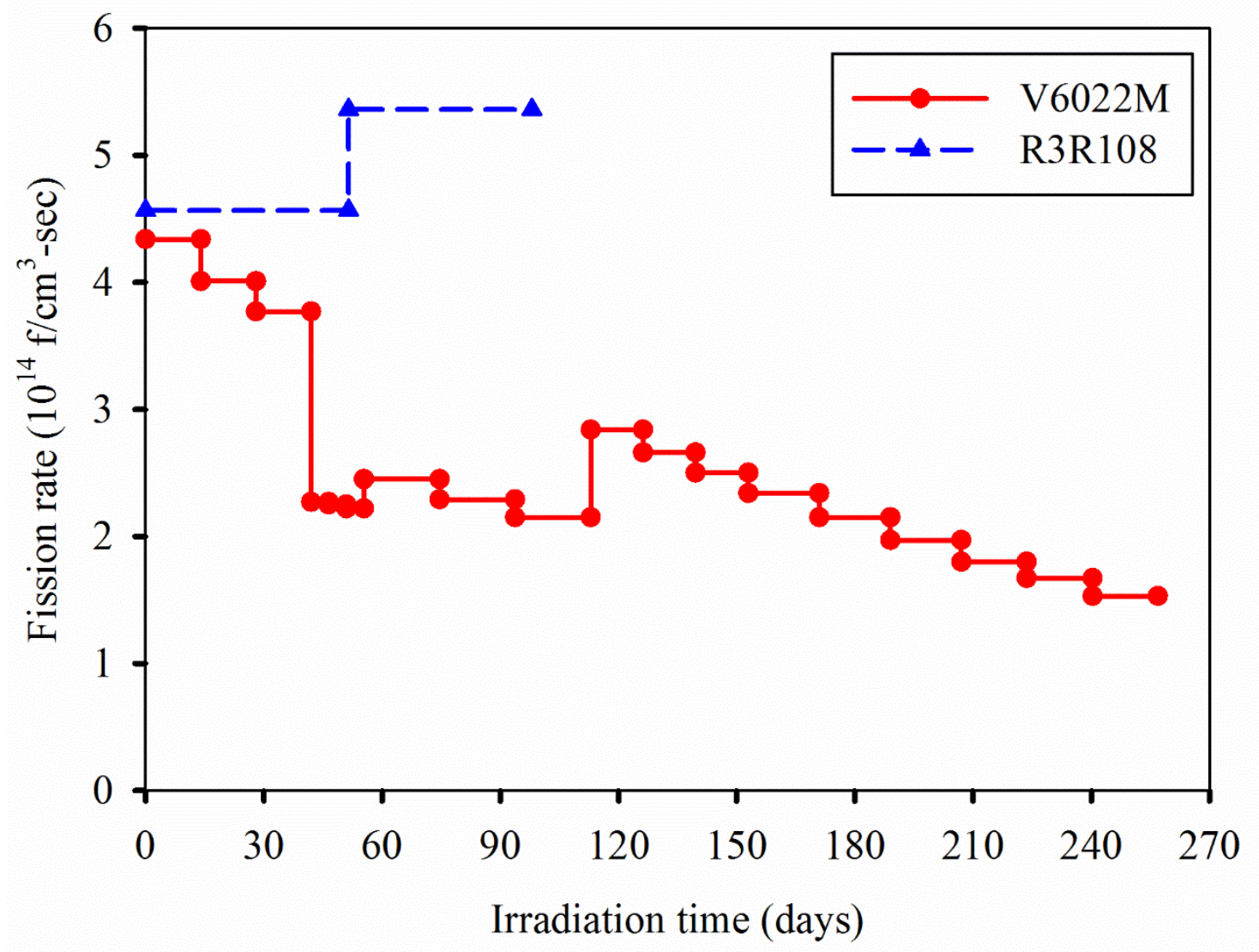

Fig. 3 Fission rate histories at the meat axial and transverse center. 


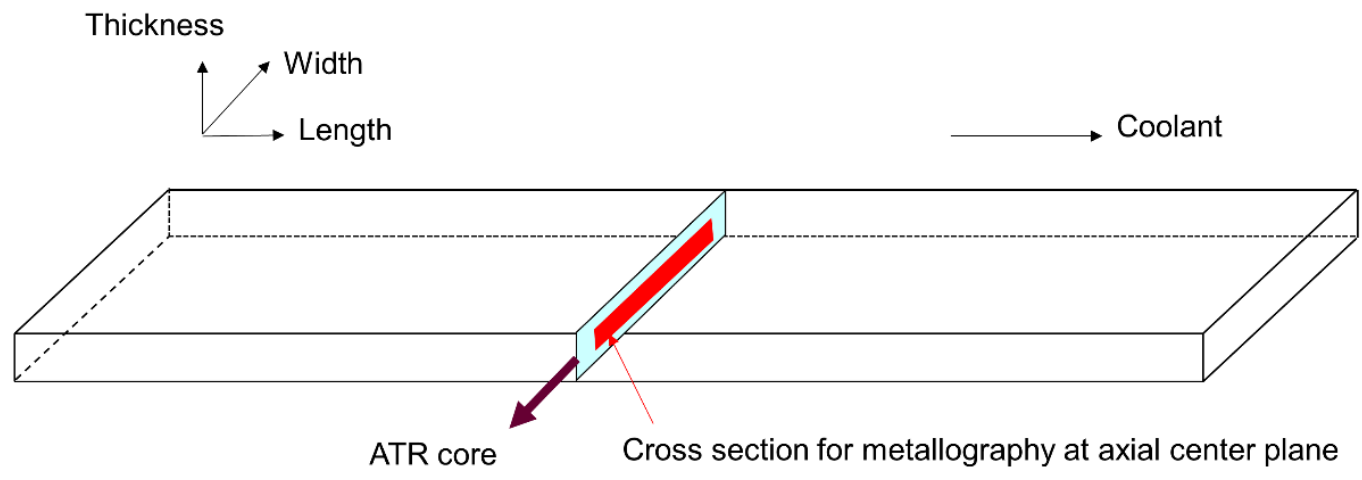

Fig. 4 Schematic illustrating PIE location of test plates. 

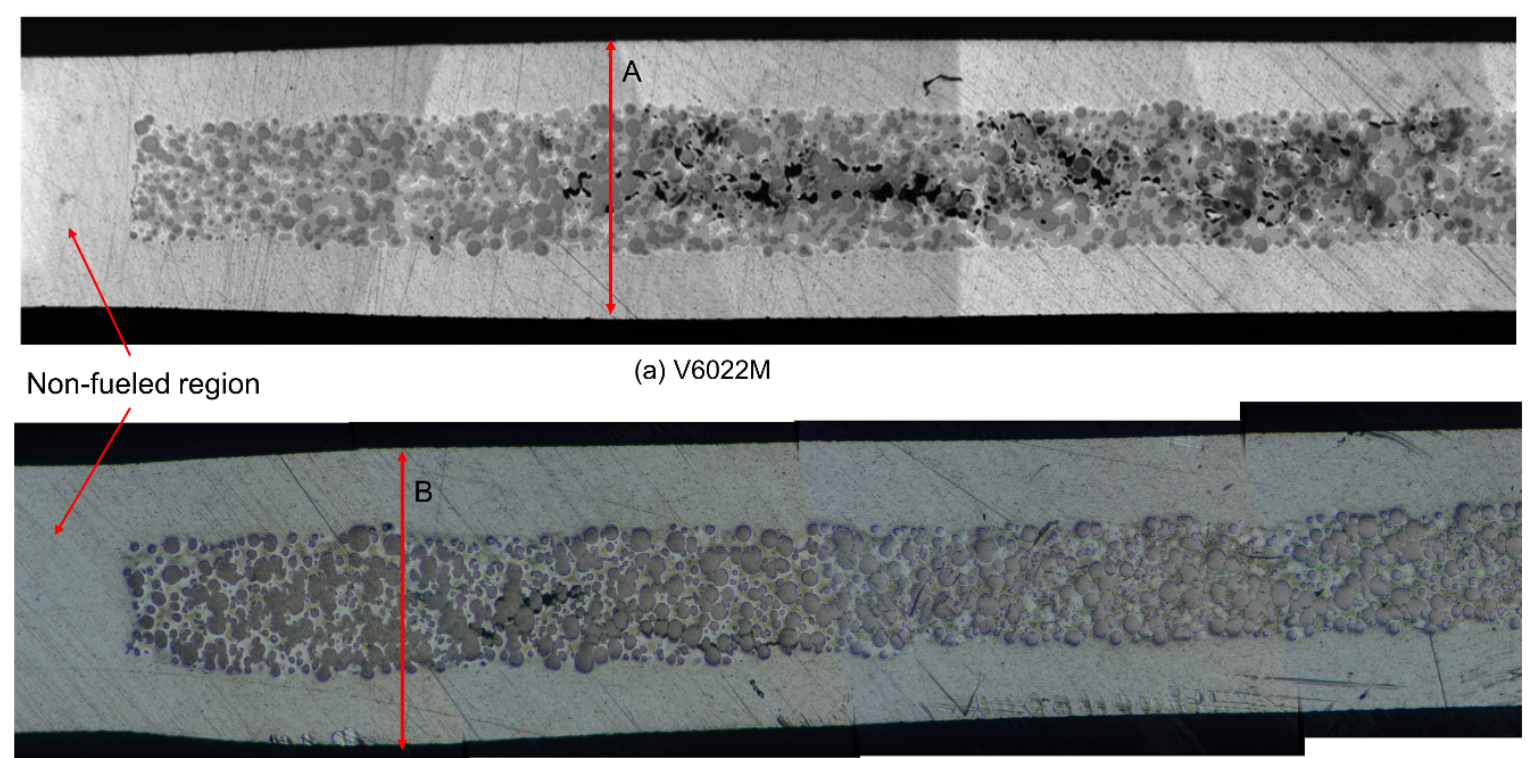

(b) R3R108

Fig. 5 OM images of cross-sections taken at PIE of two plates. The darkest particles are U-Mo fuel, the brightest is the Al matrix, and the gray phase in between is IL. The arrows marked by A and B show the peak plate thicknesses. 


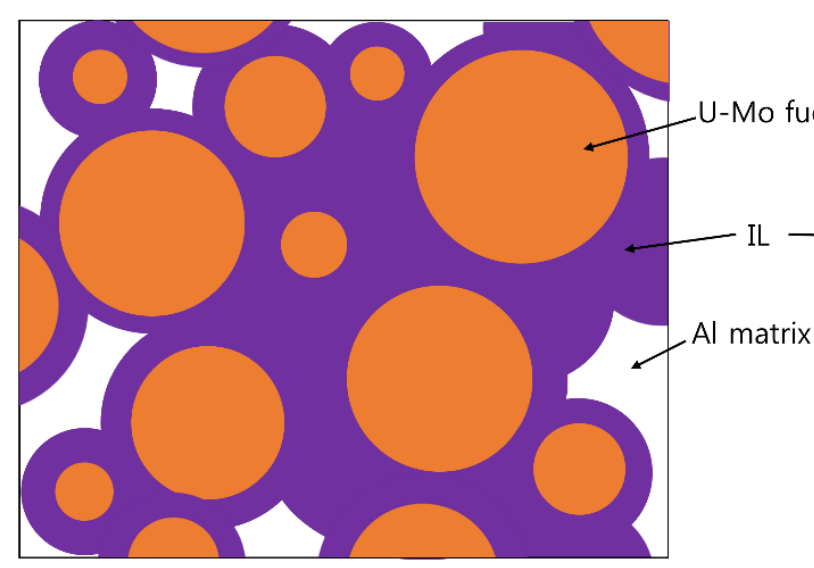

(a) V6022M

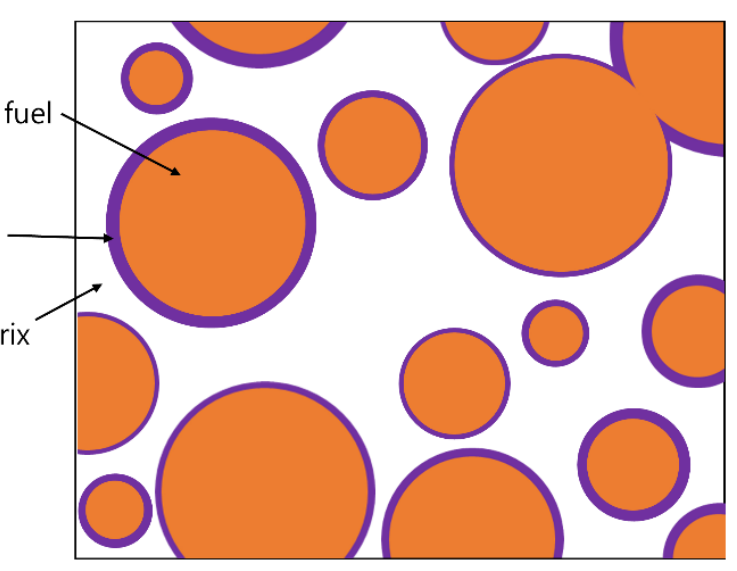

(b) R3R108

Fig. 6 Schematics illustrating the difference in microstructure between the plates at their peak plate thickness locations. The network of ILs is the continuous phase for V6022M, whereas the $\mathrm{Al}$ matrix is the continuous phase for R3R108. 


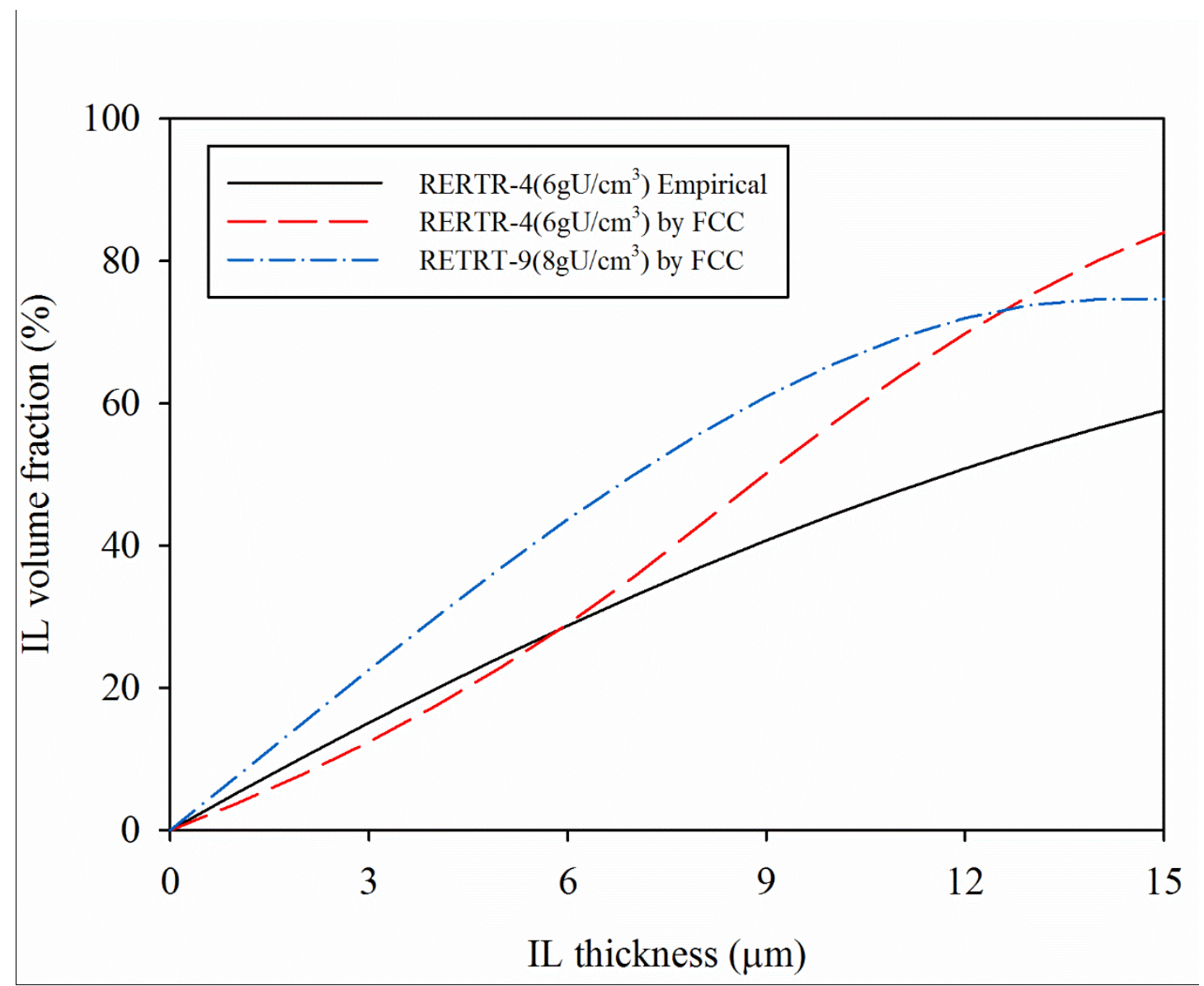

Fig. 7 IL volume fractions as a function of IL thickness for plates with $6 \mathrm{gU} / \mathrm{cm}^{3}$ and $8 \mathrm{gU} / \mathrm{cm}^{3}$ uranium loadings form the RERTR-4 and RERTR-9 test campaigns. 


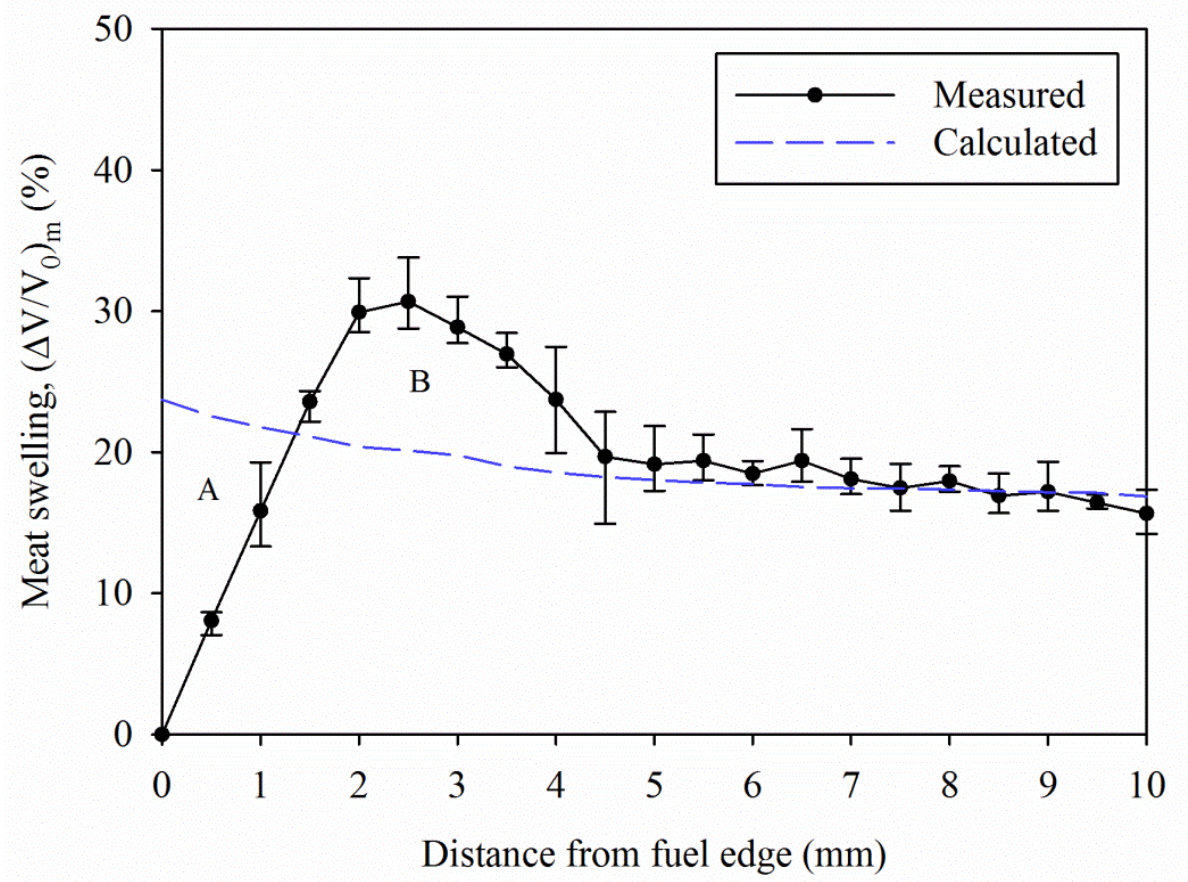

(a) V6022M

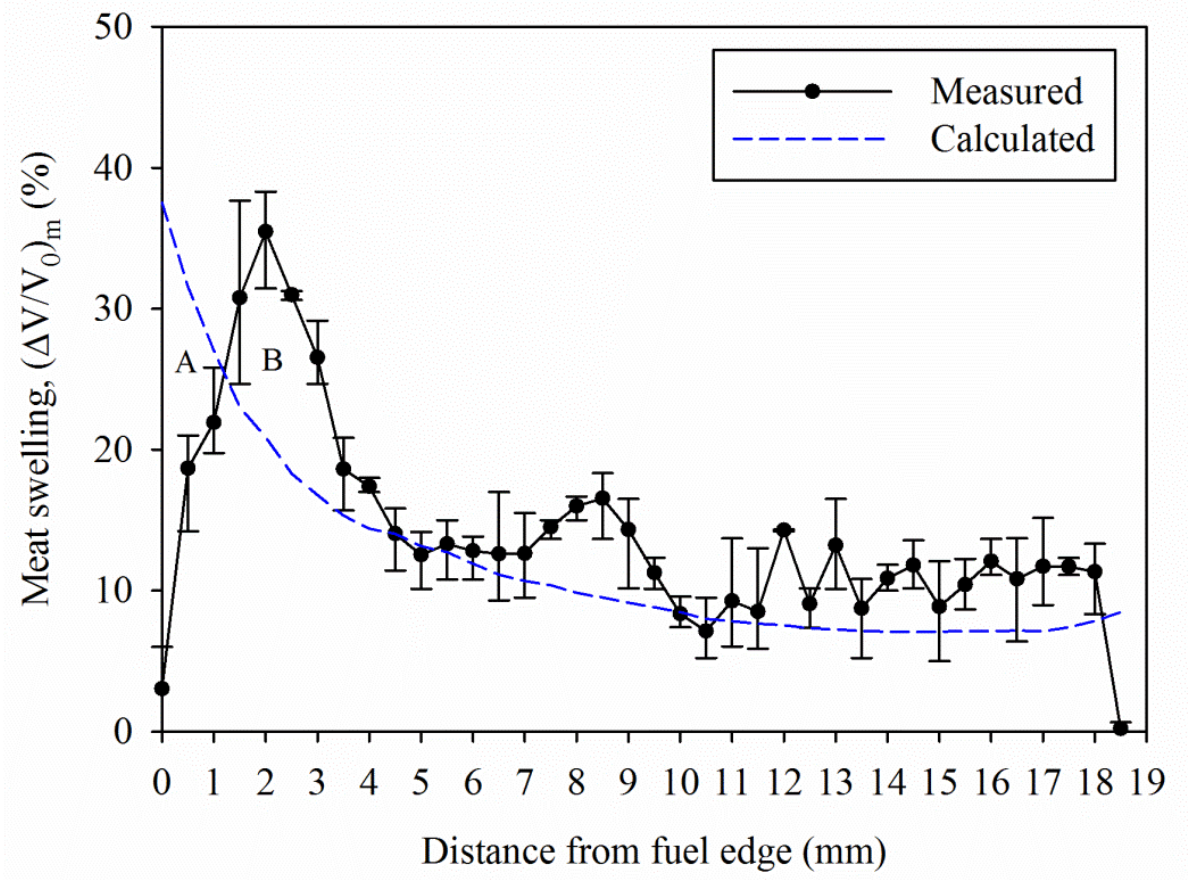

(b) R3R108

Fig. 8 Comparison between the measured and predicted swelling. 
*Dimension in $\mathrm{mm}$

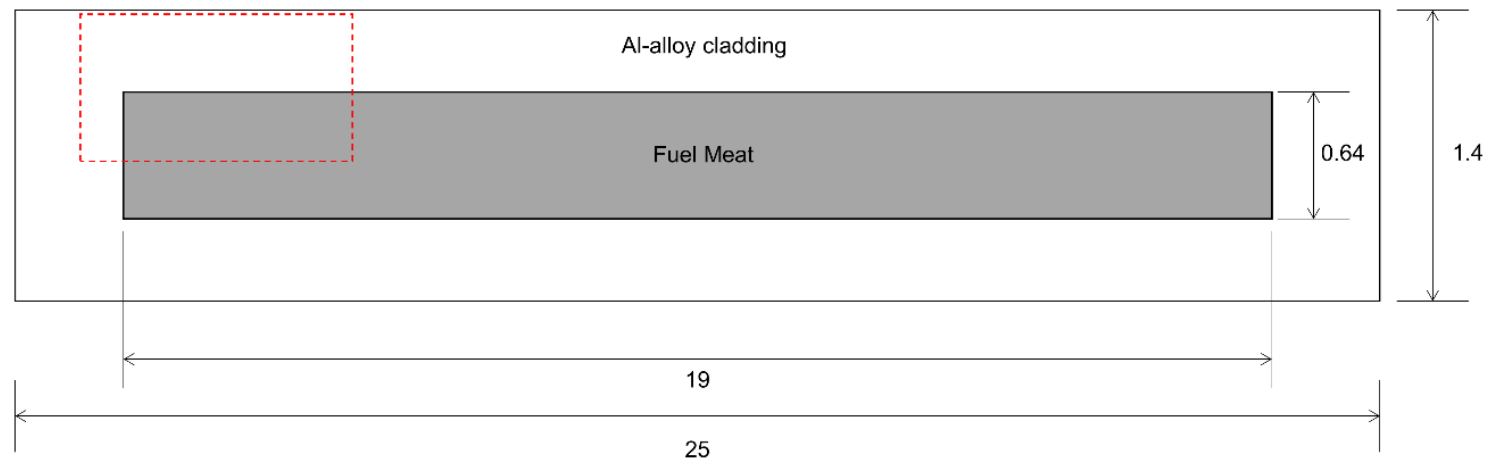

(a) Schematic of fuel plates cross section

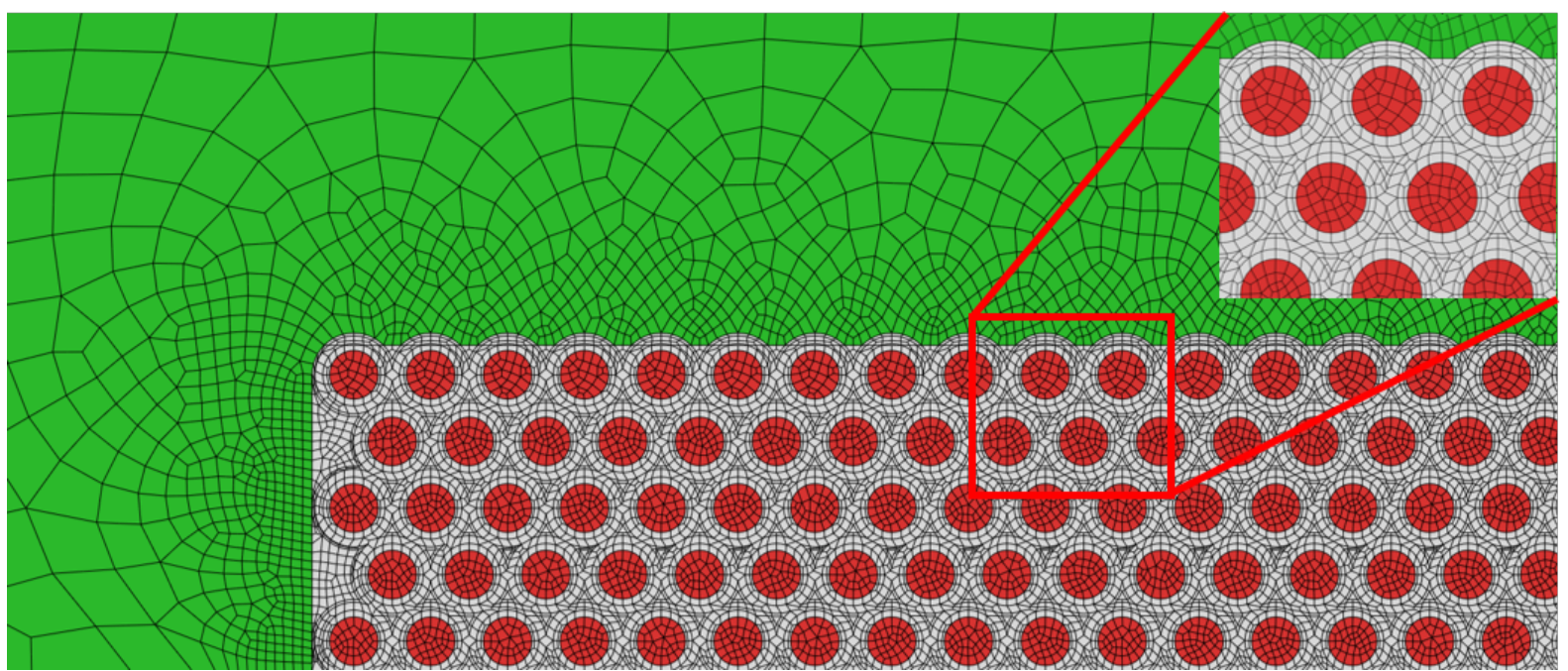

(b) V6022M 


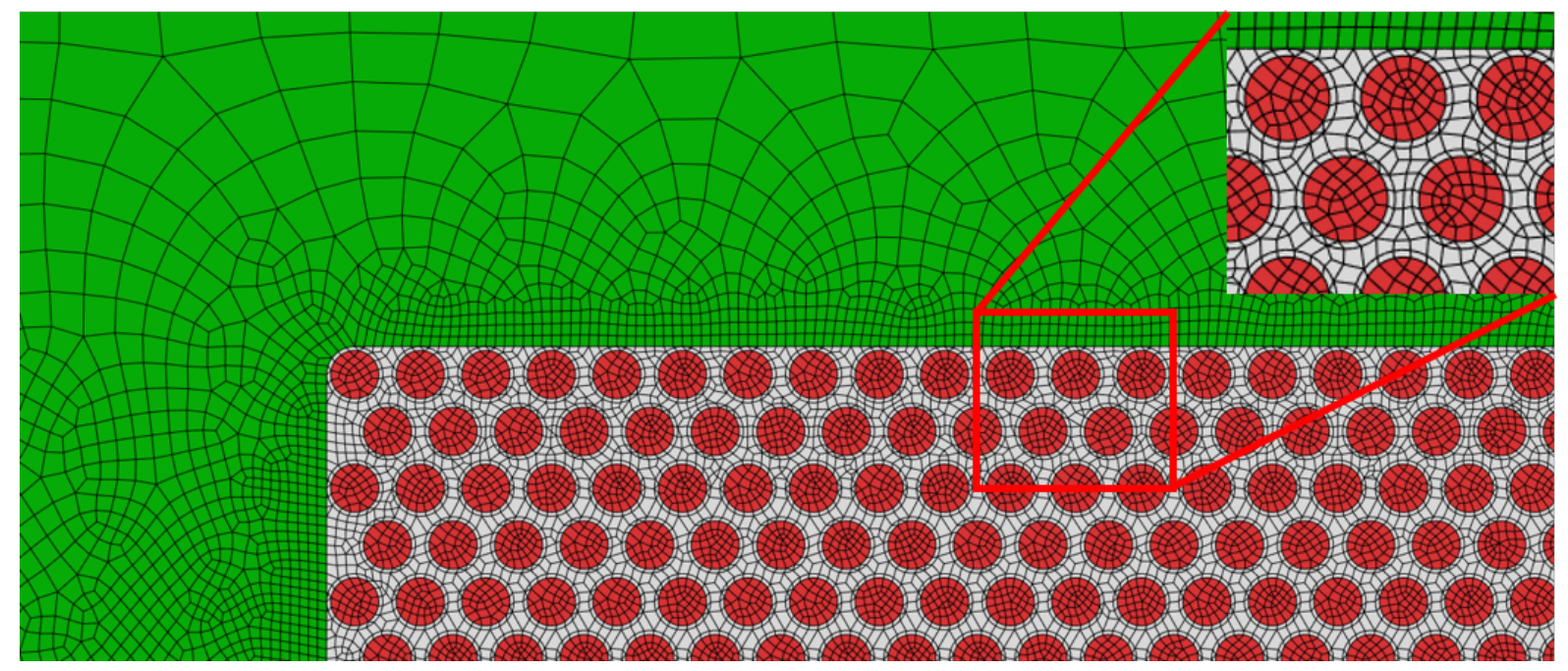

(c) R3R108

Fig. 9 (a) Schematics of fuel plate cross section and mesh configuration for finite element modeling of (b) V6022M and (c) R3R108.

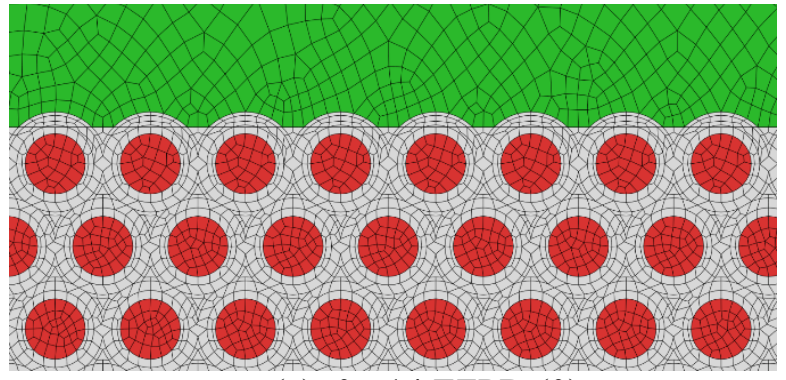

(a) 0 - 14 EFPD $(0)$

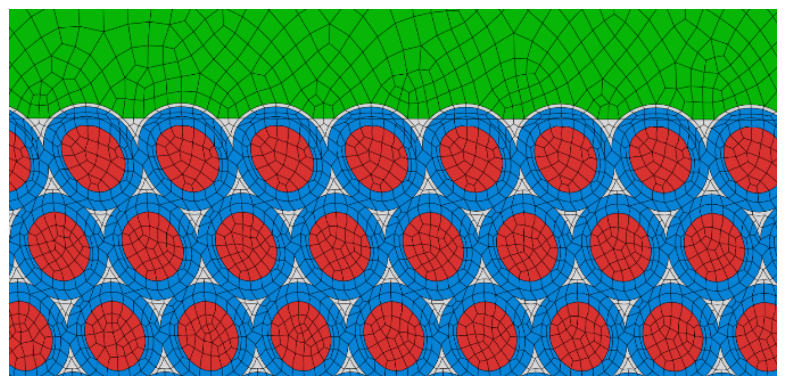

(c) 75 - $204 \operatorname{EFPD}(15)$

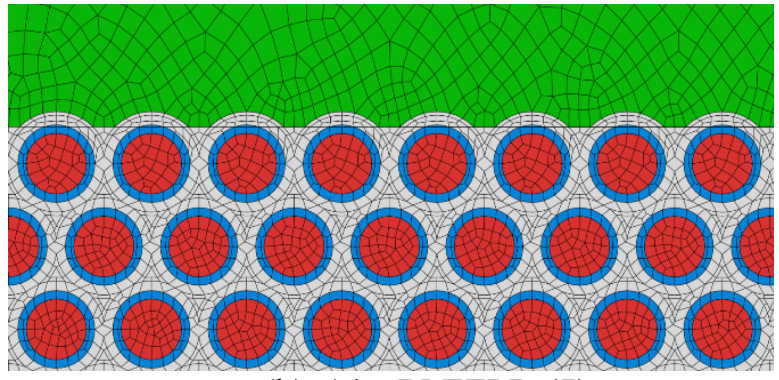

(b) 14 - 75 EFPD (7)

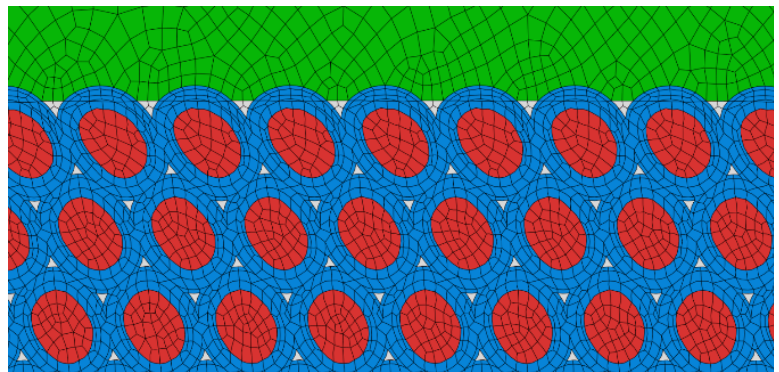

(d) $204-257$ EFPD (18)

Fig. 10 Evolution of interaction layer growth at different irradiation times for V6022M. 


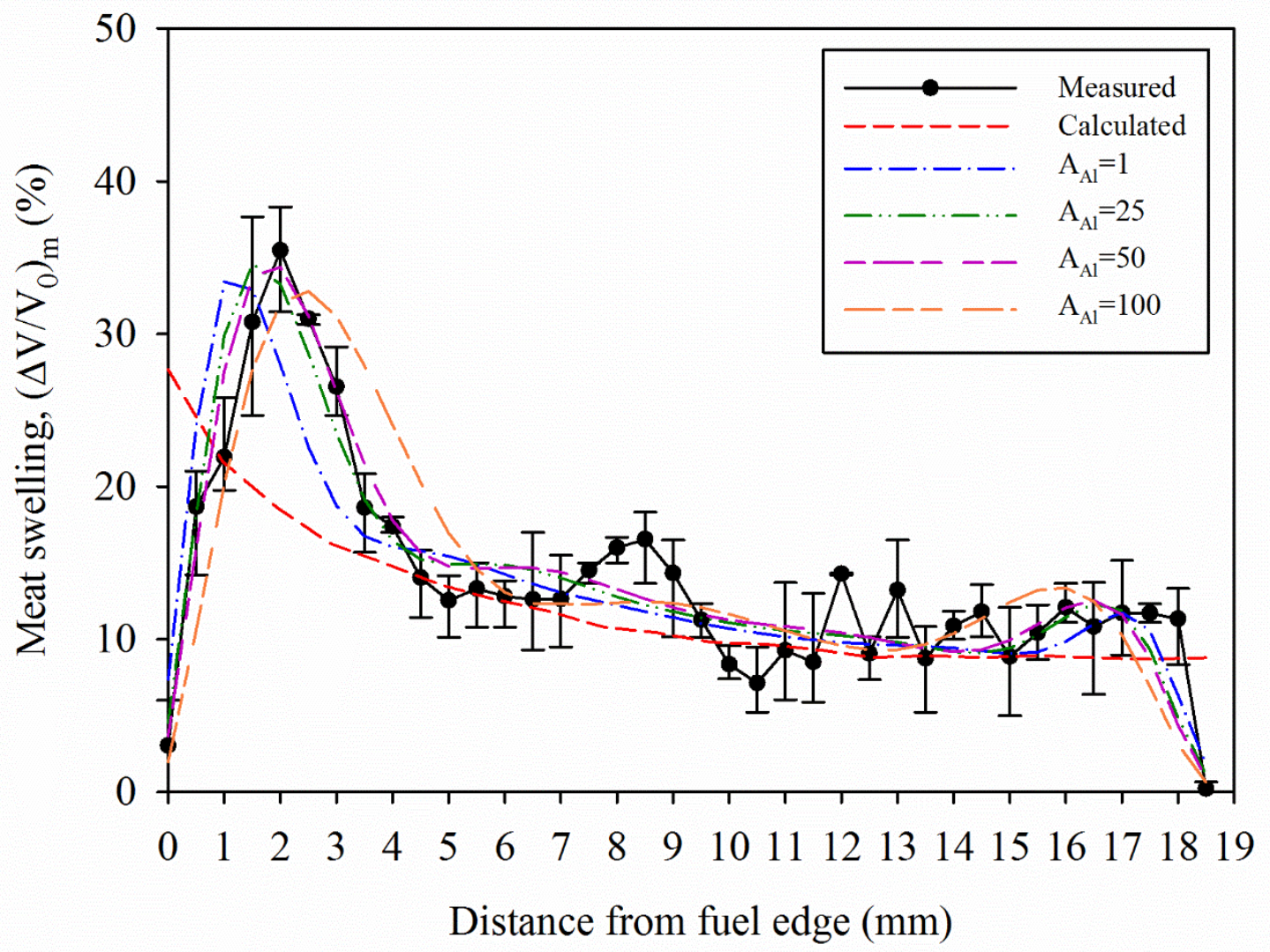

Fig. 11 Comparison of the measured meat swelling, the calculated meat swelling and ABAQUS simulation with different $\mathrm{Al}$ creep rates for R3R108 plate. 


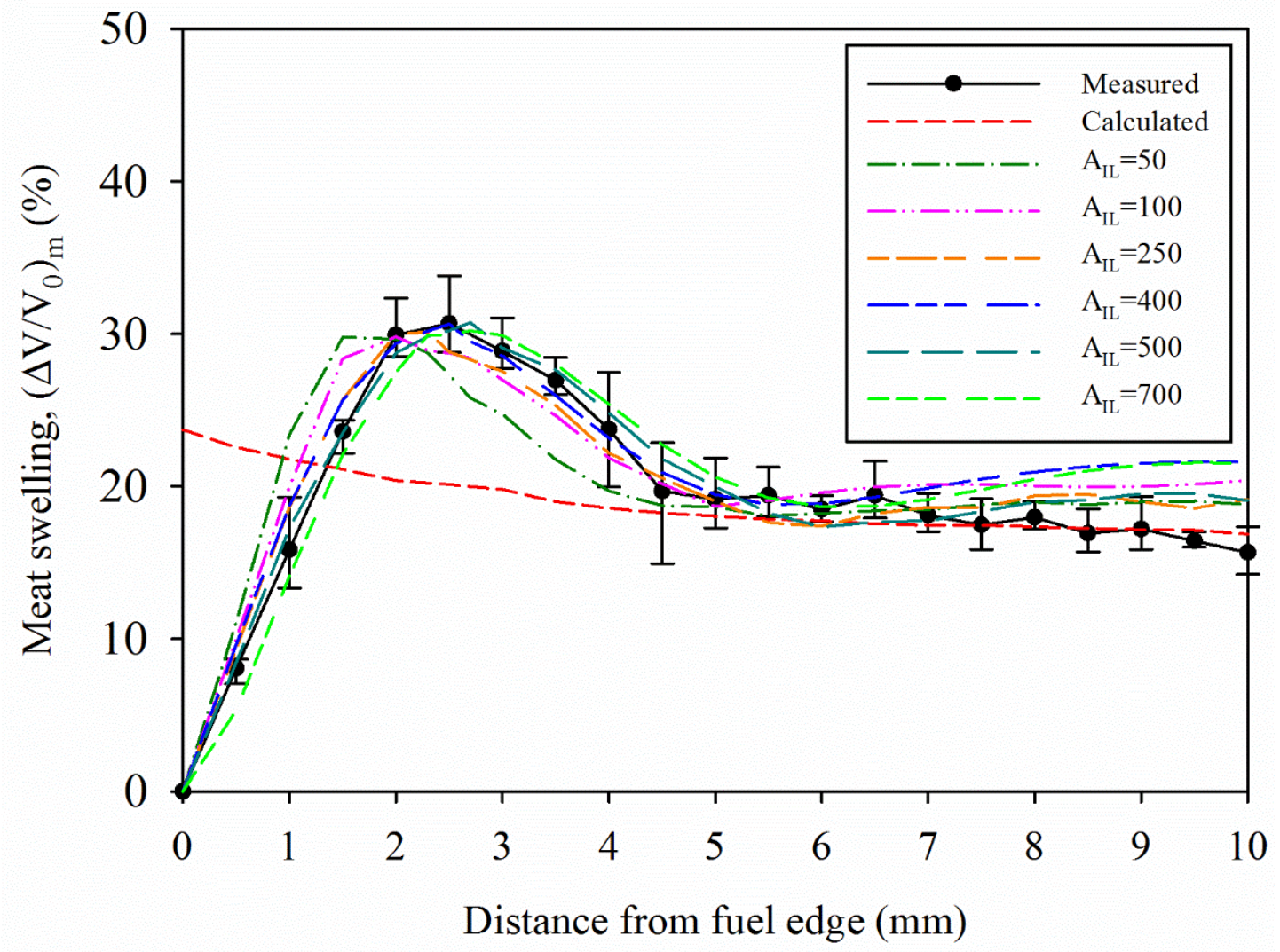

Fig. 12 Comparison of the measured meat swelling, the calculated and ABAQUS simulations with different creep rates constant of IL for V6022M plate. 


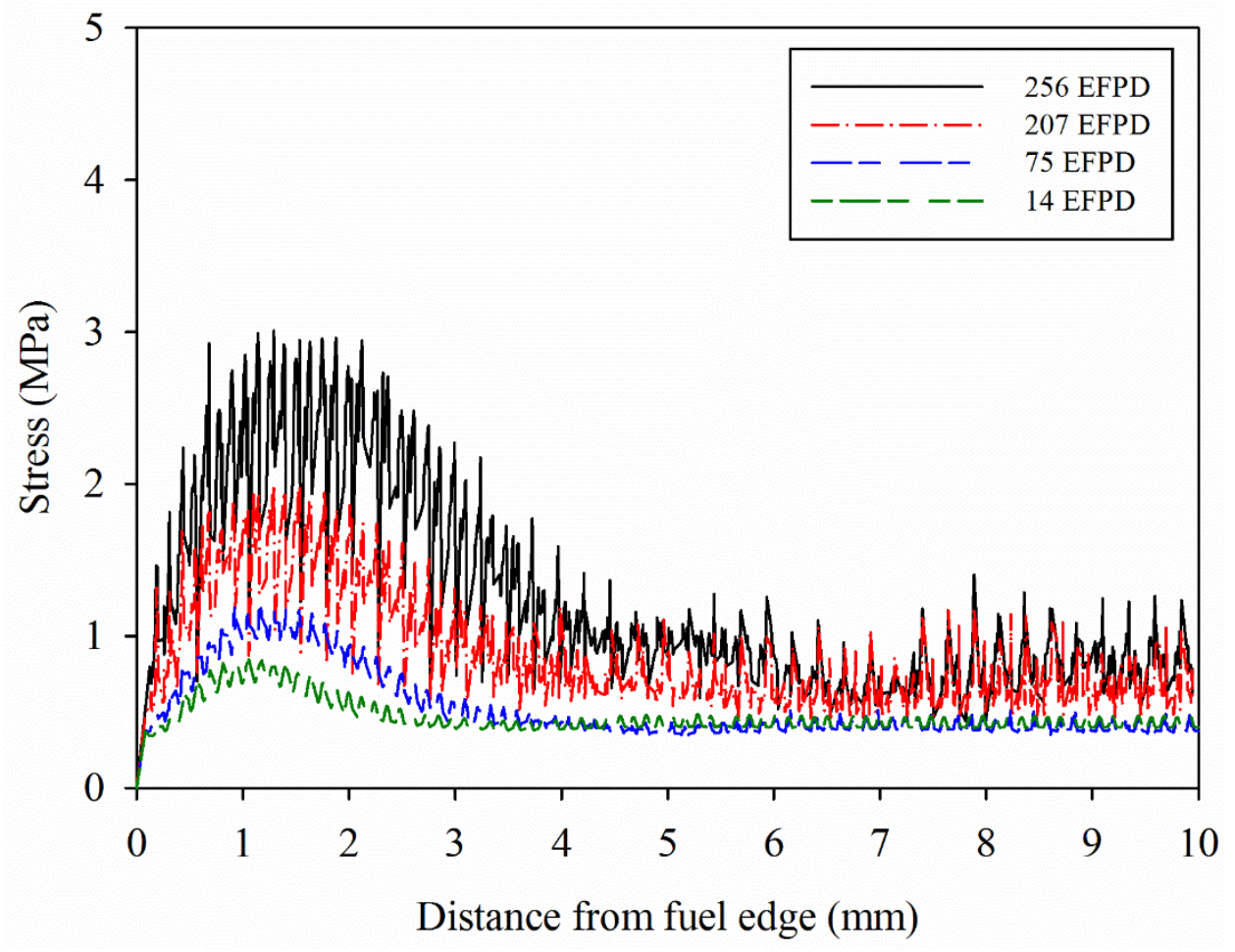

(a) V6022M

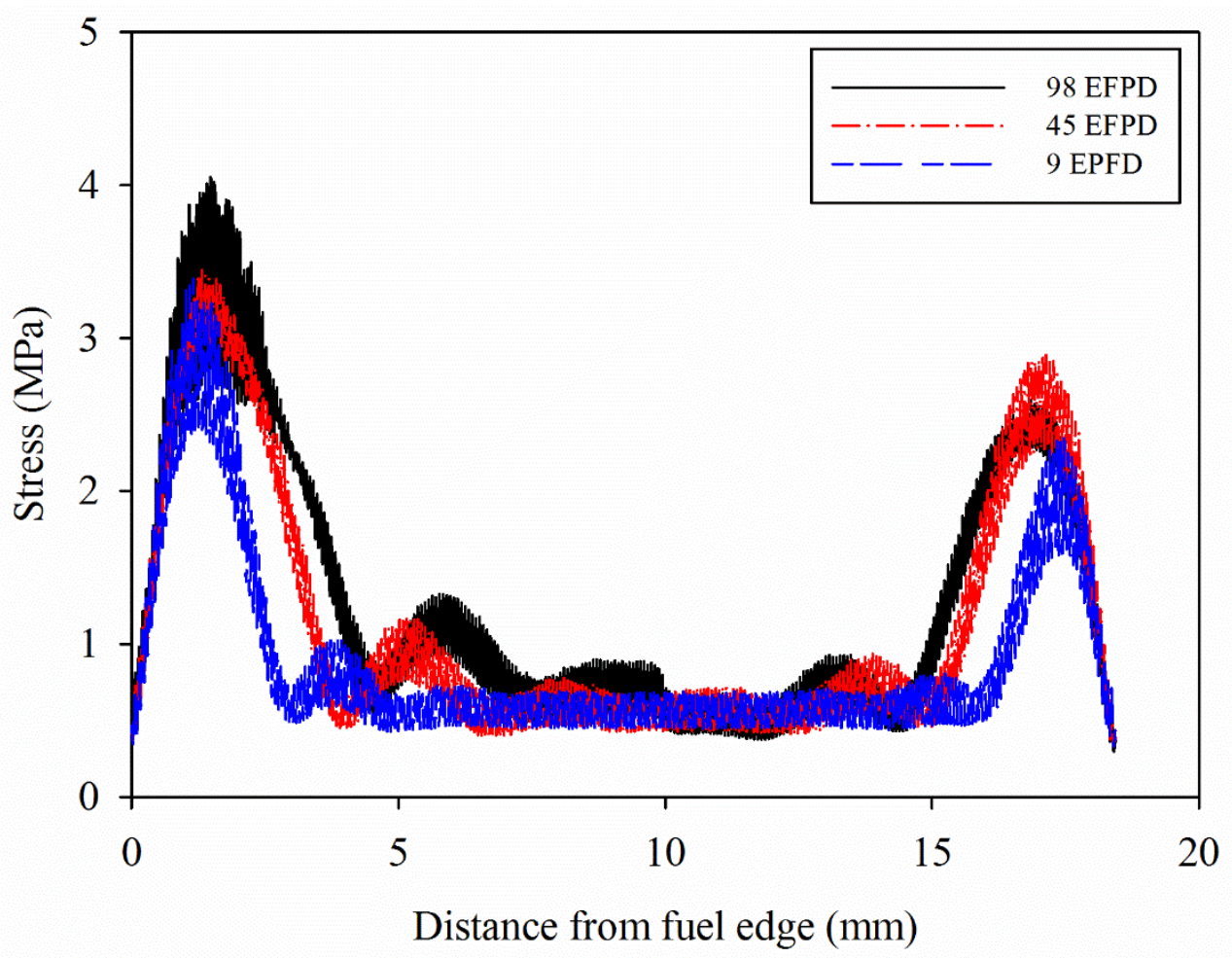

(b) R3R108

Fig. 13 Von Mises stress for fuel particles corresponding to the creep rate constants of IL and Al 
matrix $\left(\mathrm{A}_{\mathrm{IL}}=400 \times 10^{-25} \mathrm{~cm}^{3} / \mathrm{MPa}, \mathrm{A}_{\mathrm{Al}}=50 \times 10^{-25} \mathrm{~cm}^{3} / \mathrm{MPa}\right)$.

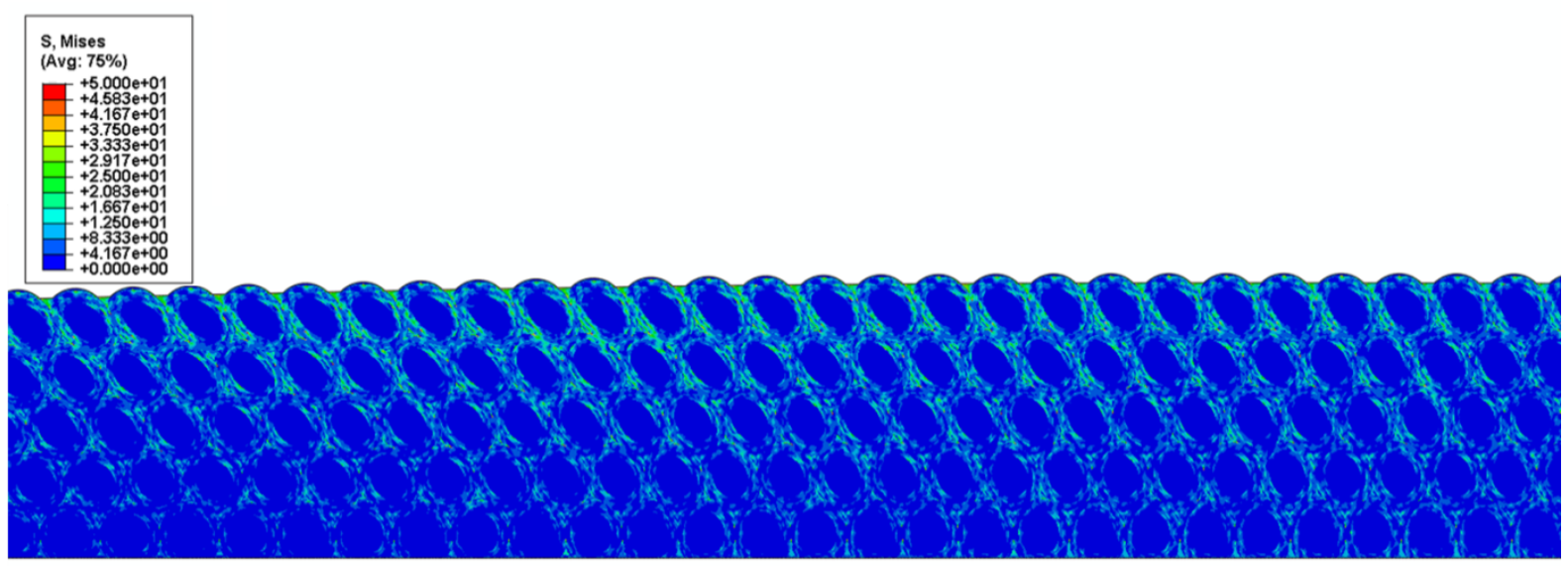

(a) V6022M

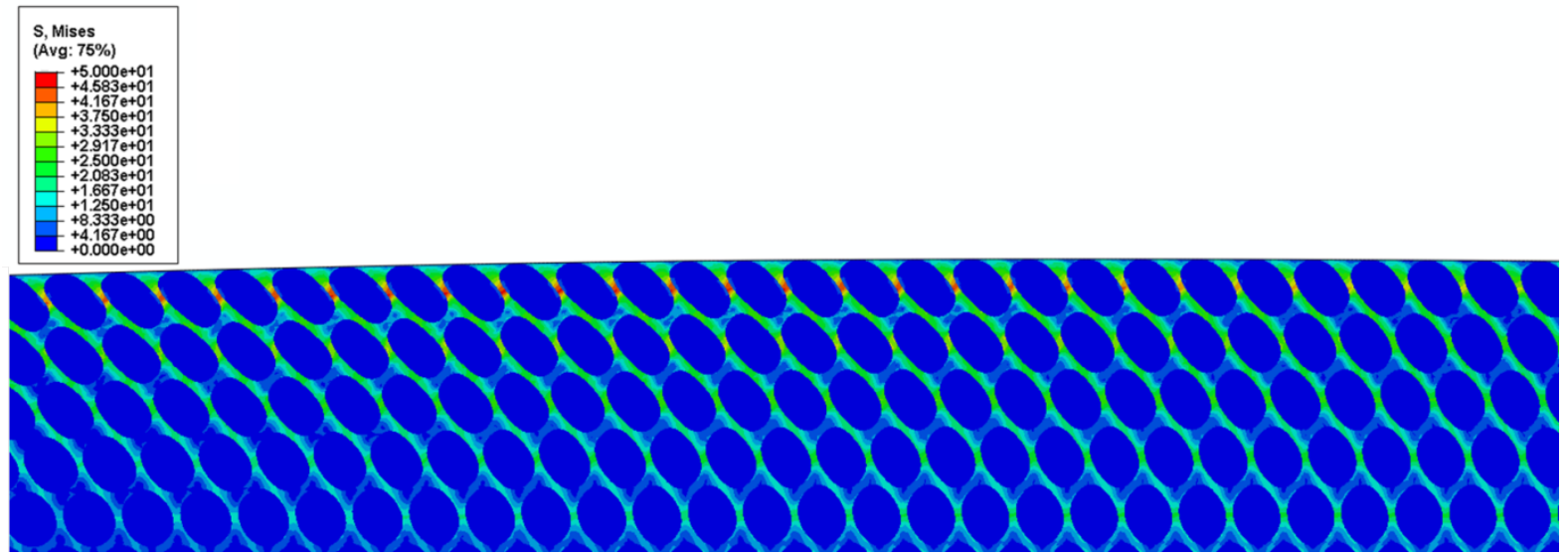

(b) R3R018

Fig. 14 Contour of the equivalent stress by meat swelling in the region of the peak meat thickness location. 


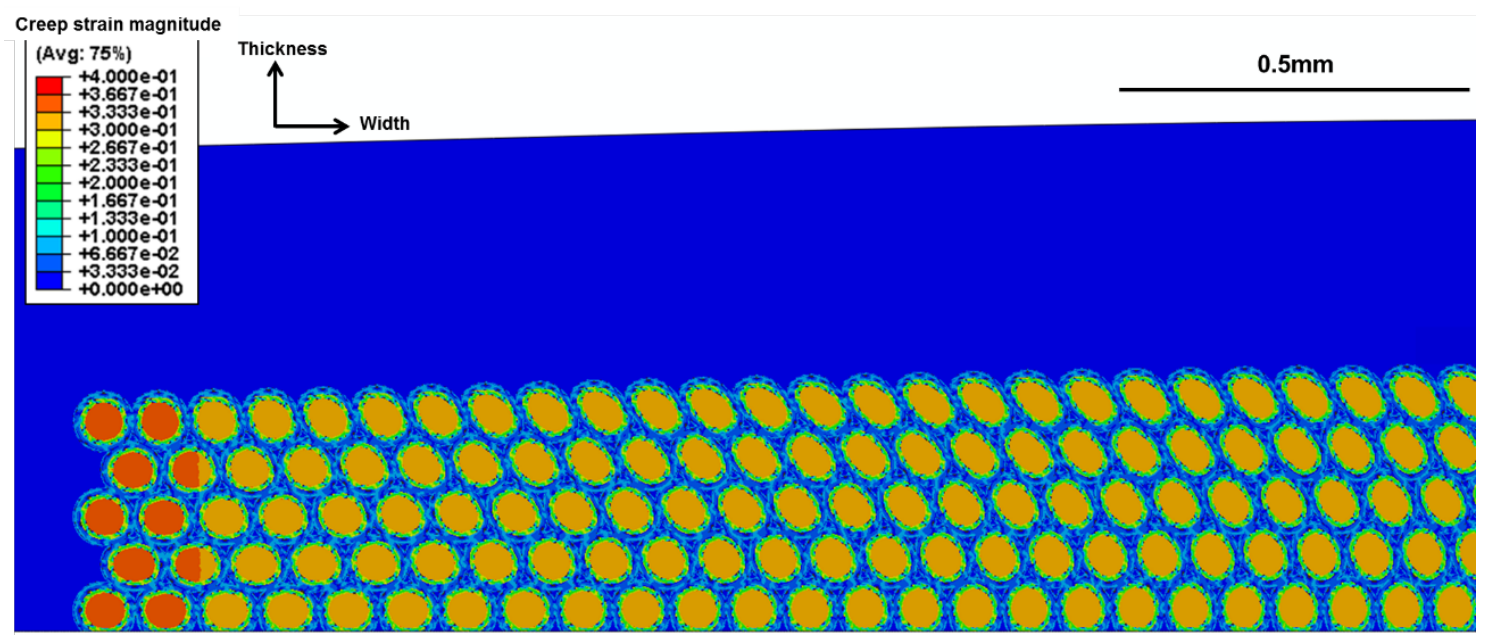

(a) V6022M

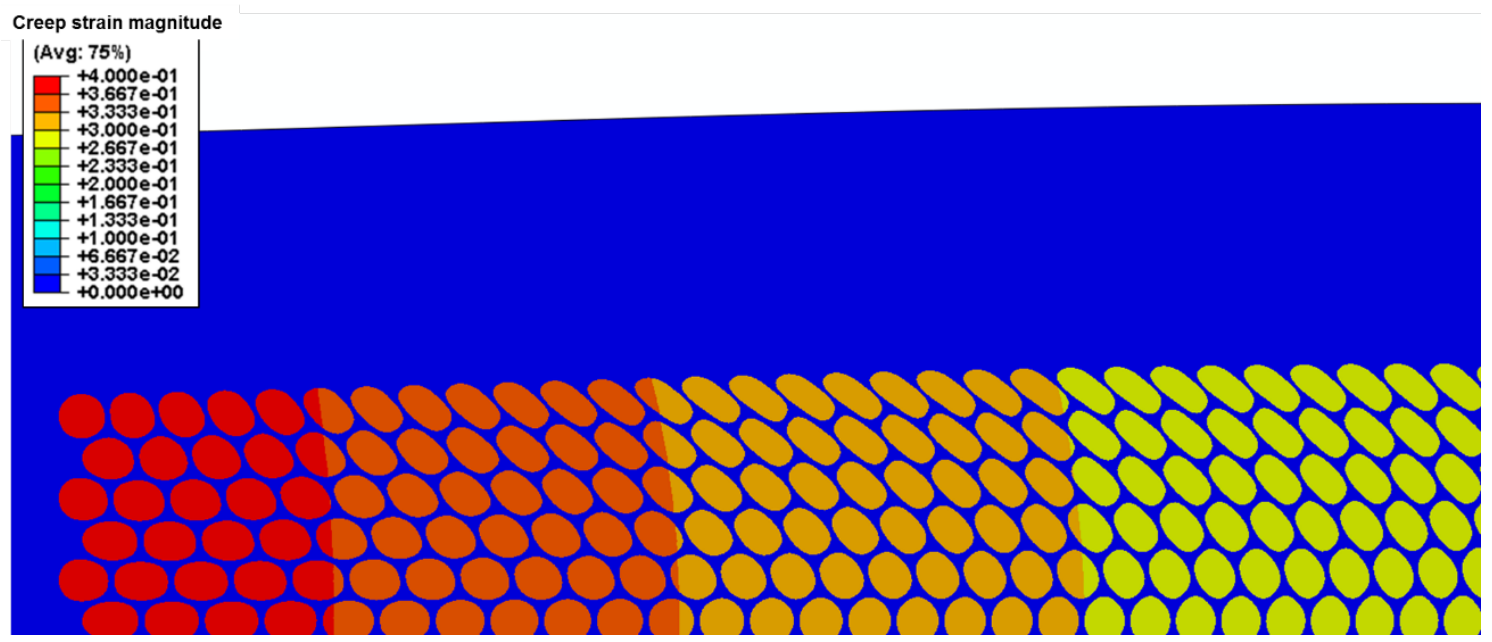

(b) R3R018

Fig. 15 Contour of meat volume expansion by meat swelling and creep induced mass relocation from the meat edge to the peak meat thickness region. 


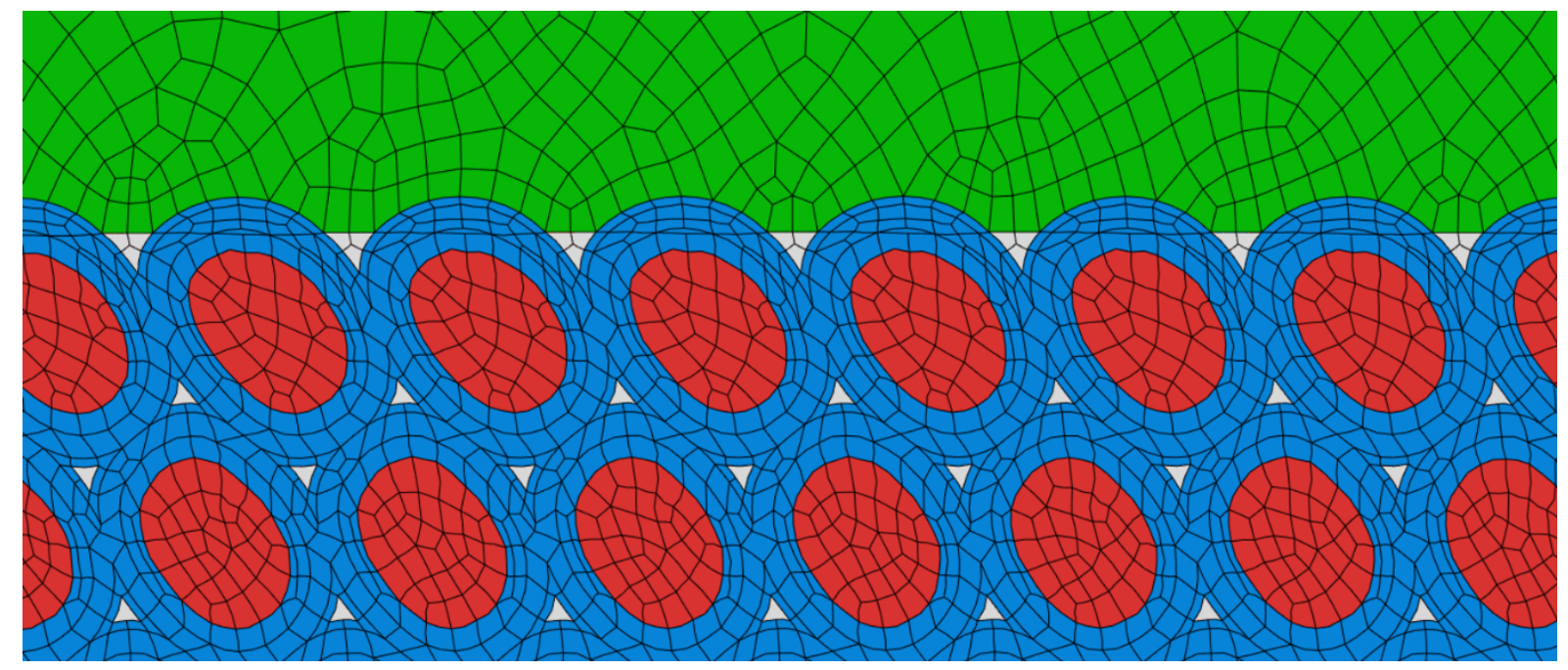

(a) V6022M at $257 \mathrm{EFPD}$

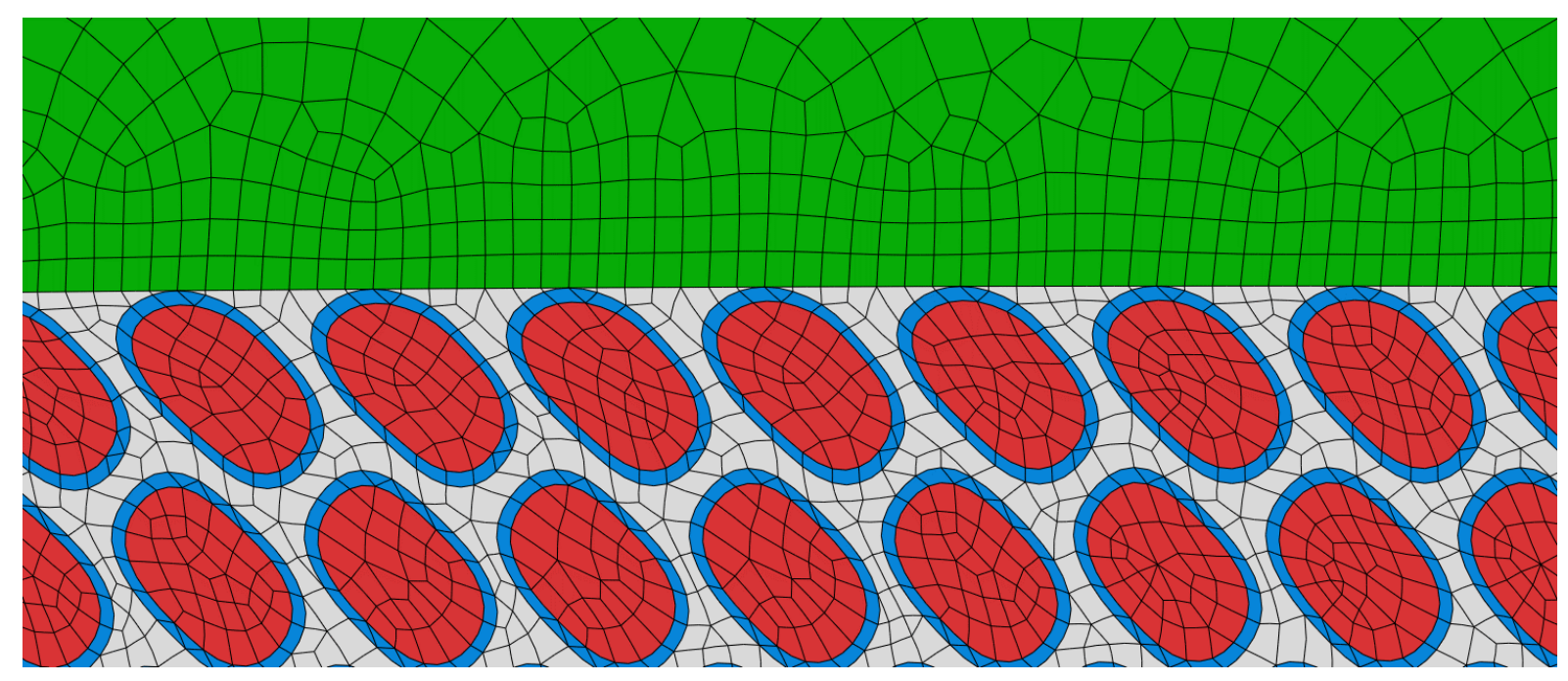

(b) R3R108 at 98 EFPD

Fig. 16 Comparison of fuel particle deformation in the peak meat thickness location at the end of life. 


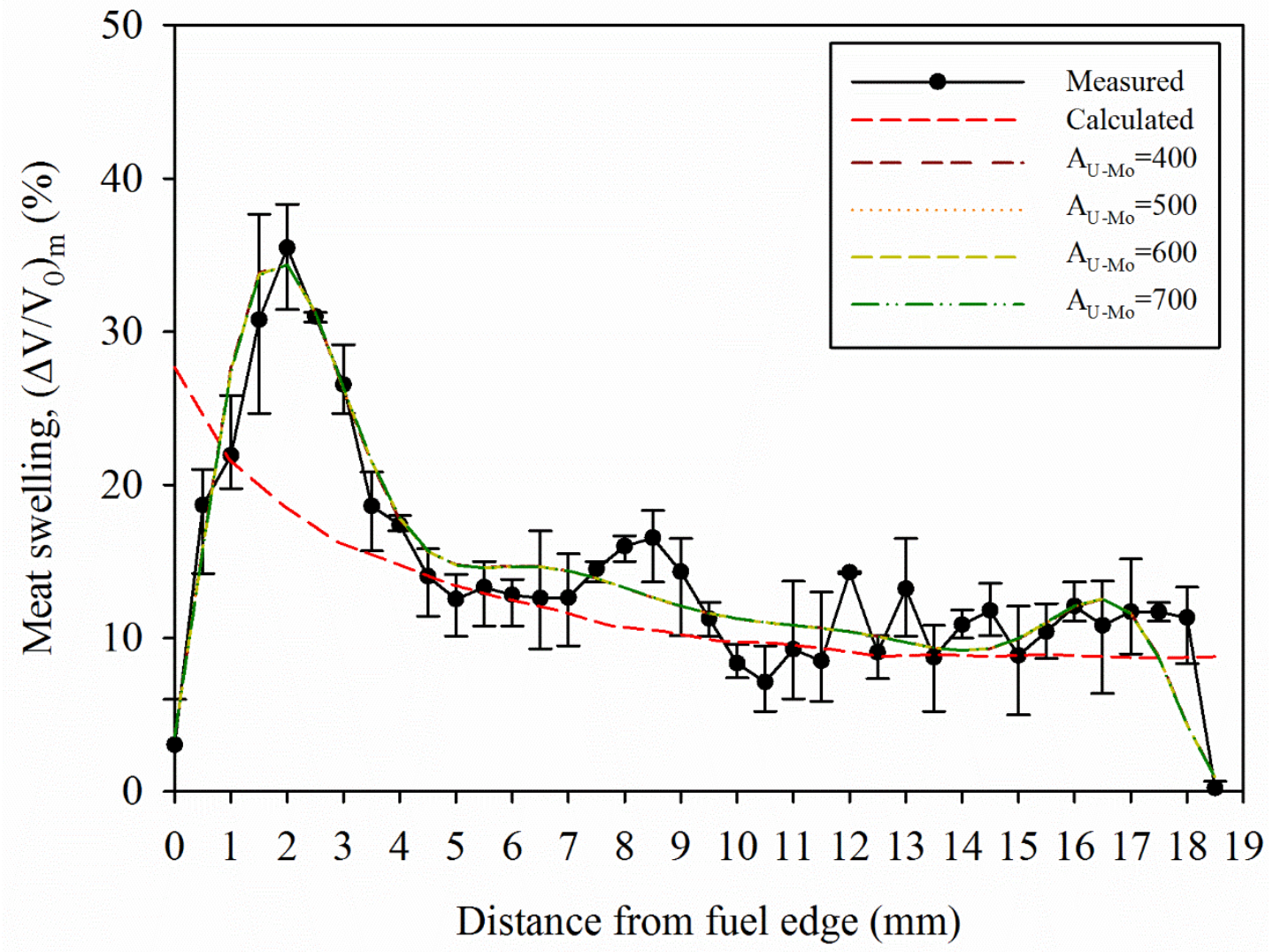

Fig. 17 Effect of the creep rate constant of the U-Mo fuel particles in R3R108. The creep rate constants of the $\mathrm{Al}$ matrix $\left(\mathrm{A}_{\mathrm{Al}}\right)$ and $\mathrm{IL}\left(\mathrm{A}_{\mathrm{IL}}\right)$ were set at $50 \times 10^{-25} \mathrm{~cm}^{3} / \mathrm{MPa}$ and $400 \times 10^{-25} \mathrm{~cm}^{3} / \mathrm{MPa}$, respectively. 


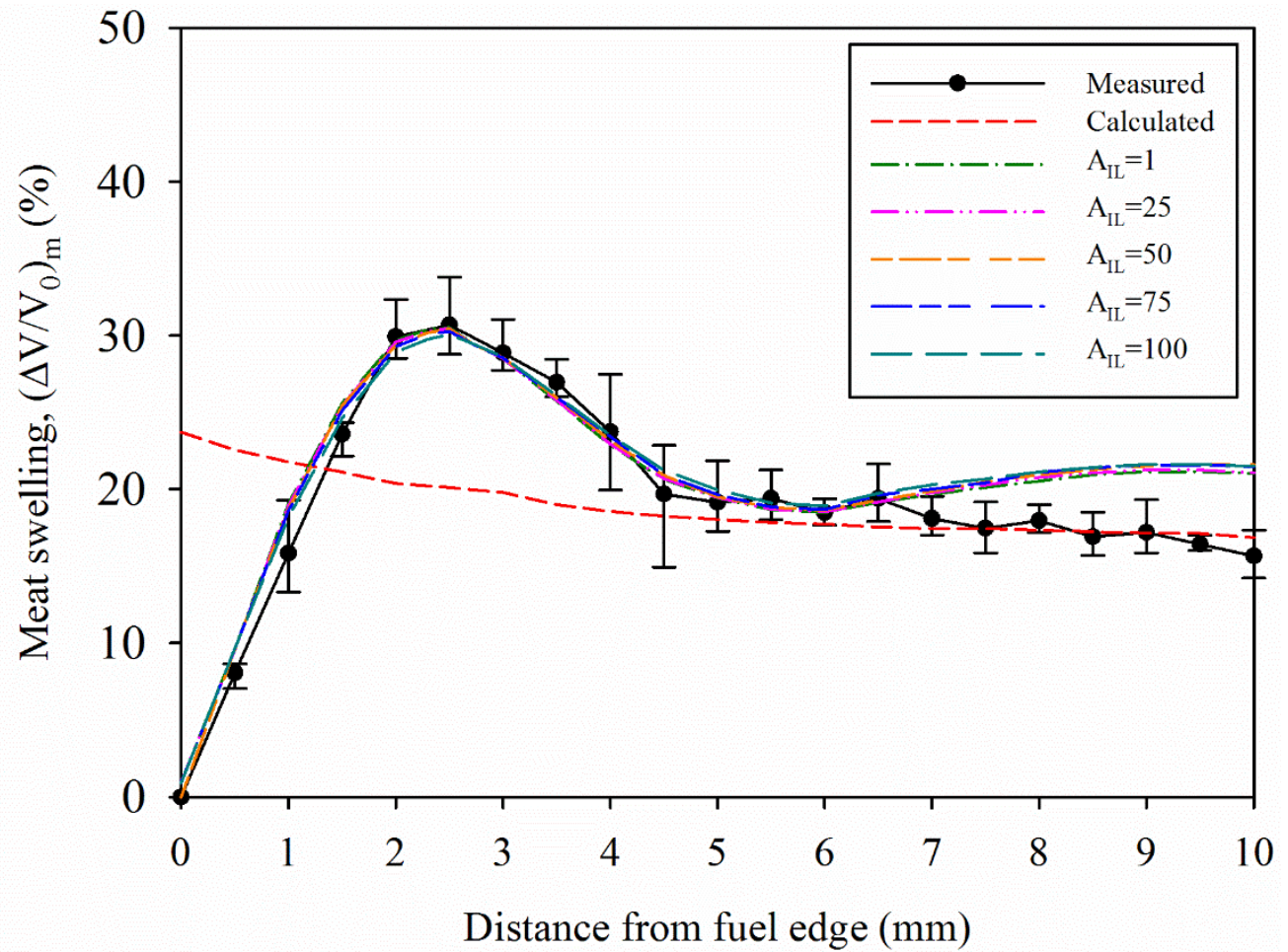

(a) V6022M with $\mathrm{A}_{\mathrm{U}-\mathrm{Mo}}=500 \times 10^{-25} \mathrm{~cm}^{3} / \mathrm{MPa}$ and $\mathrm{A}_{\mathrm{IL}}=400 \times 10^{-25} \mathrm{~cm}^{3} / \mathrm{MPa}$

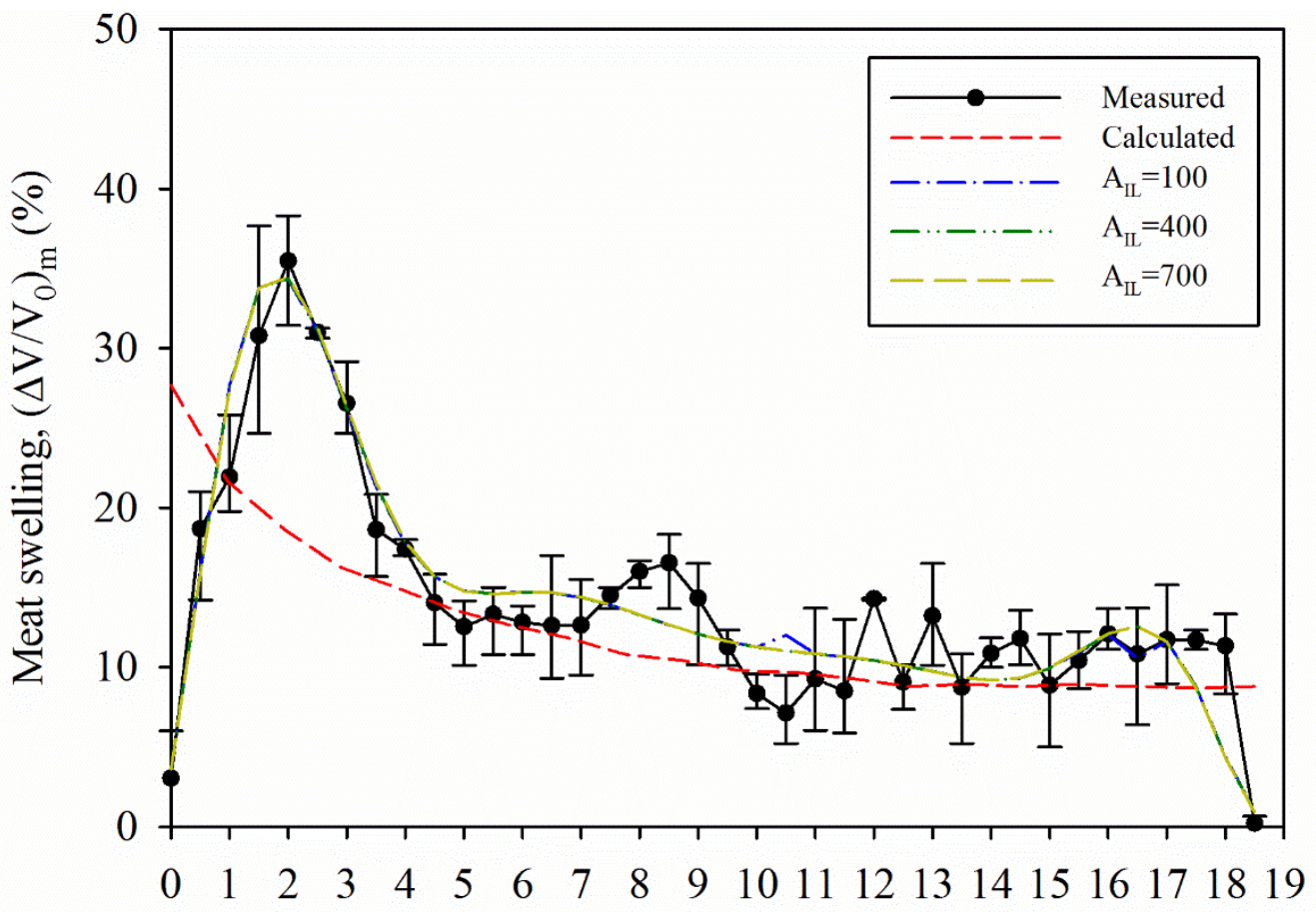

Distance from fuel edge ( $\mathrm{mm})$

(b) R3R108 with $\mathrm{A}_{\mathrm{U}-\mathrm{Mo}}=500 \times 10^{-25} \mathrm{~cm}^{3} / \mathrm{MPa}$ and $\mathrm{A}_{\mathrm{Al}}=50 \times 10^{-25} \mathrm{~cm}^{3} / \mathrm{MPa}$

Fig. 18 Effect of the creep rate constant of (a) Al matrix in V6022M and (b) IL in R3R108. 


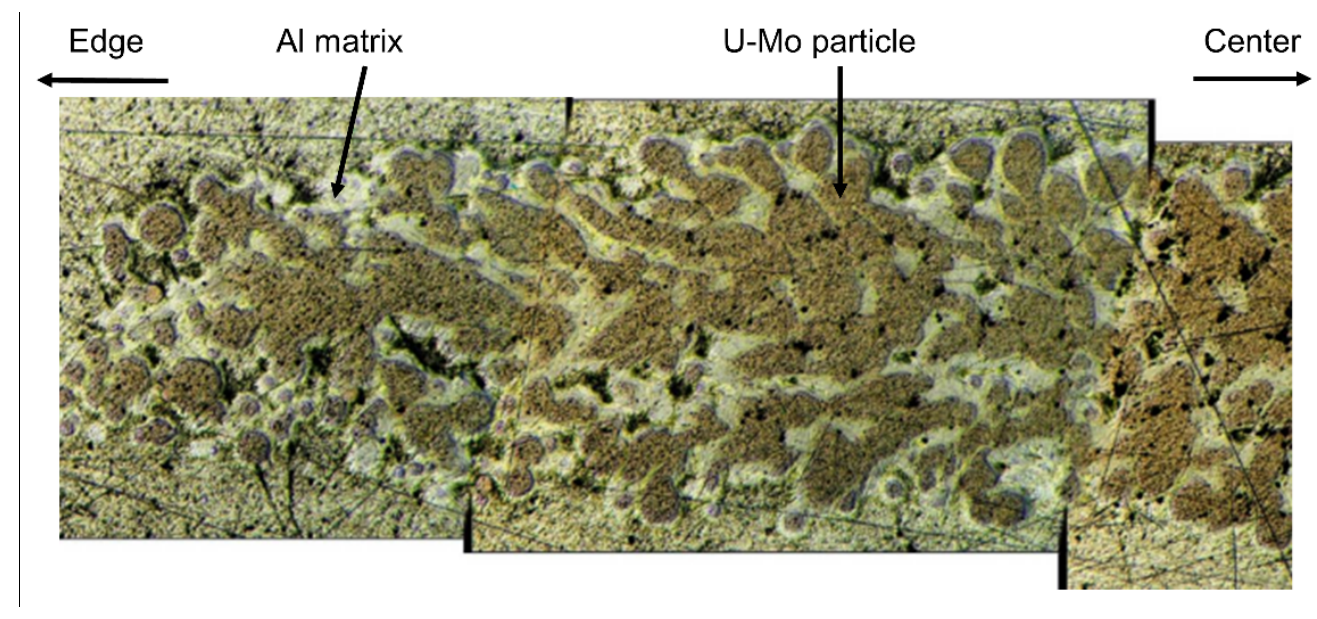

Fig. 19 OM of the fuel meat end region of RERTR-9 plate (R6R018). The fission density in U-Mo particle is $\sim 10 \times 10^{21} \mathrm{f} / \mathrm{cm}^{3}$. 